\title{
Mutation rates in seeds and seed-banking influence substitution rates across the angiosperm phylogeny
}

\author{
Marcel Dann ${ }^{1+}$ \\ Sidonie Bellot ${ }^{2+}$ \\ Sylwia Schepella ${ }^{2}$ \\ Hanno Schaefer ${ }^{2}$ \\ Aurélien Tellier ${ }^{1}$ \\ ${ }^{1}$ Section of Population Genetics, Department of Plant Sciences, Technical University of \\ Munich, Liesel Beckmann Strasse 2, 85354 Freising, Germany \\ ${ }^{2}$ Plant Biodiversity Research, Department Ecology \& Ecosystem Management, Technical \\ University of Munich, Emil-Ramann Strasse 2, 85354 Freising, Germany \\ ${ }^{t}$ Both authors contributed equally. \\ "Corresponding author: tellier@wzw.tum.de \\ Section of Population Genetics, Department of Plant Sciences, Technical University of \\ Munich, Liesel Beckmann Strasse 2, 85354 Freising, Germany
}

\section{Summary}

1) Background. Seed-banking (the ability to persist in the soil over many generations) is usually considered as a dormant stage where genotypes are "stored" as a bet-hedging strategy in response to unpredictable environments. However, seed dormancy may instead have consequences for the integrity of the DNA and generate novel mutations.

2) Methods. We address this paradox by building phylogenies based on the plastomes and nuclear ITS of species belonging to ten angiosperm clades. In each clade, the substitution rate (branch-length) of a seed-banking species is compared with that of a closely-related non-seed-banking species.

3) Results. Seed-banking species show as high or higher substitution rates than non-seedbanking species, and therefore mutations occur in dormant seeds at a rate at least as high as in above-ground plants. Moreover, seed born mutations have the same probability to reach fixation as those from above ground. Our results are robust to differences in selection, generation time, and polymorphism.

4) Conclusions. Mutations occurring in seeds, and thus seed-banking, affect the population diversity of plant species, and are observable at the macro-evolutionary scale. Our study has consequences for seed storage projects, since the stored seeds are likely to accumulate mutations at a higher rate than previously thought.

Key words: mutation rate, seed, seed banking, dormancy, substitution rate 


\section{Introduction}

Seed-banking or long term dormancy is a prevalent strategy in many plant species but also in bacteria and invertebrates. This bet-hedging strategy evolves to maximize the geometric fitness of the population under variable and unpredictable environmental conditions (Brown \& Venable, 1986; Evans \& Dennehy, 2005). Seed-banking has evolved multiple times in angiosperms (Willis et al., 2014), and is frequently seen as an adaptation to desert habitats (Brown \& Venable, 1986; Pake \& Venable, 1996). Multiple adaptations at the physiological level allow dormancy, such as low metabolism or thick pericarp (Finch-Savage \& Leubner-Metzger, 2006). Different types of dormancy can be distinguished based on the physiology and triggers to lift up the dormant state (Willis et al., 2014), and result in different types of seed-banks depending on the maximal length of dormancy: transient (< one year), short term persistent (one to five years), and long term persistent ( $\geq$ five years) (Thompson et al., 1997; Baskin \& Baskin, 2014).

Seed-banking generates a so-called storage effect of diversity in the soil which has known consequences at the population level such as increasing genetic diversity (Templeton \& Levin, 1979; Nunney, 2002; Lundemo et al., 2009), slowing down natural selection (Hairston Jr \& De Stasio Jr, 1988; Koopmann et al., 2016), promoting balanced polymorphism (Turelli et al., 2001; Tellier \& Brown, 2009) and decreasing genetic differentiation among populations (Vitalis et al., 2004; Falahati-Anbaran et al., 2014). The storage effect has also the consequence to buffer population size changes (Nunney, 2002), and decrease population extinction rates, which is known as the "rescue effect" (Brown \& Kodric-Brown, 1977). The chief effect of longer term seed-banking is thus to increase the observable genetic polymorphism within a population both in seeds and in above-ground plants, irrespective of the origin of the mutation (above-ground plants or seeds).

In addition to the storage effect, Levin (Levin, 1990) proposed that seed-banks would not only conserve alleles over generations, but could also be a source of new alleles arising from mutations accumulating during a long stay in the soil. This view is supported by physiological and molecular biology studies demonstrating that DNA degradation occurs in seeds (Abdalla \& Roberts, 1969; Cheah \& Osborne, 1978; Murata et al., 1982; Chauhan \& Swaminathan, 1984; Dourado \& Roberts, 1984a; Dourado \& Roberts, 1984b; Dandoy et al., 1987). Repair mechanisms of DNA in seeds have been recently elucidated, linking the maintenance of genome stability with the progression through germination (Waterworth et al., 2016). It follows therefore that species with longer seed-banks are expected to exhibit a higher rate of neutral, deleterious and advantageous mutations in seeds (Levin, 1990). This seems to be confirmed by a study of 16 pairs of closely-related seed-banking and nonseed-banking angiosperm species where the seed-bankers were found to have higher substitution rates (Whittle, 2006). However, this preliminary work was limited to the $<500$ bp nuclear ITS region and did not control for possible confounding factors. In contrast to those findings, ecologists and population geneticists have predominantly assumed that mutations occurring in seeds are chiefly deleterious, and that neutral or advantageous mutations occur only in above-ground plants (Kaj et al., 2001; Vitalis et al., 2004; Tellier et al., 2011; Koopmann et al., 2016). Indeed, a meta-analysis comparing genetic diversity in the soil seed-banks and above-ground plants has revealed only marginal differences (Honnay et al., 2008). This is not surprising considering the short time scales of the study, and that the above-ground population is in effect a sub-sample of the seed-bank (Lundemo et al., 2009). However, a slight excess of rare alleles could be observed in the seed-banks (Honnay et al., 2008) based on various markers which provide imprecise knowledge about the mutation rate (e.g. AFLP or microsatellites). This excess has been attributed to possible selection at the seedling stage against deleterious mutations arising in seeds (Vitalis et al., 2004). To resolve this contradictory evidence, we analyze large chloroplast DNA regions 
$(>>10 \mathrm{~kb})$ and the nuclear ITS of selected angiosperm species with different seed-bank lengths, and quantify the amount of new mutations arising in seeds that become fixed at the macro-evolutionary time scale.

Resolving this issue has theoretical and empirical importance. First, in models investigating the effect of seed-banks on neutral and selected diversity in plant genomes (Kaj et al., 2001; Vitalis et al., 2004; Tellier et al., 2011; Koopmann et al., 2016) the per site per generation mutation rate is a crucial parameter, influencing the inference of short time scale evolutionary parameters (Živković \& Tellier, 2012). Second, at the phylogenetic time scale, substitution rates are scaled per generation which means that the length of seedbanking may factor indirectly in branch length (Charlesworth, 1994) under the assumption that mutations occurring in seeds may reach fixation. Differences in seed-banking would thus have to be considered when investigating the origin of substitution rate heterogeneity in species trees, and when deciding a priori between strict or relaxed molecular clock models to time-calibrate a phylogeny. The effect of seed-banking and the mutation rate in seeds has so far been ignored in phylogenetic studies. Third, knowing if mutations occur in seeds and at which rate is of high relevance to sustain seed storage of plant species for conservation purposes (e.g., Millenium Seed-bank, http://www.kew.org/scienceconservation/collections/millennium-seed-bank).

In this study, we investigate the long-term effect of seed mutations on species substitution rates. We aimed to compare the substitution rates of species producing only transient seed-banks, i.e. short or non-seed-banking (NSB) species, and species producing long-term persistent seed-banks, i.e. seed-banking (SB) species sensu Thompson et al. (1997). In order to avoid confounding effects, we follow a "species-pair" approach as advocated in Lanfear et al. (Lanfear et al., 2010) by comparing substitution rates of closelyrelated and ecologically similar SB and NSB species forming pairs scattered across the angiosperm phylogeny (see Fig. 1). We estimate substitution rates from branch lengths obtained from the Bayesian phylogenetic analysis of 41 full (chloroplast) plastomes, 27 of which are newly sequenced and assembled for this study, while 14 are recovered from databases. These plastomes are obtained by both genome skimming of DNA from old herbarium specimens and using a newly developed protocol for chloroplast DNA enrichment. We use three different statistical tests to demonstrate that seed-banking species have increased substitution rates compared to non-seed-banking species. Furthermore, we test that this effect is not confounded by generation time or selection pressure. In conclusion, we call for more ecological studies of the intensity and age of seed-banking for individual plant lineages, and we encourage population geneticists and phylogeneticists to pay more attention to seed mutations and differences in seed-banking when they elaborate models of micro- and macro-evolution.

\section{Material and Methods}

Choice of Candidate Species. Based on a large literature search (Thompson et al., 1997; Baskin \& Baskin, 2014) ten quadruplets of species were chosen, each consisting in an ingroup with one seed-banking (SB) and one non seed-banking (NSB) species, and two other outgroup species (total of 40 species and one general outgroup, list in Table S1 and phylogeny in Fig. 1). Inside each quadruplet, the two ingroup species were chosen to be as closely-related and ecologically similar as possible. Details on the literature search and species classification as SB or NSB are provided in the Supplementary Text 1, and further description of species (longevity, generation time, habitat, sexual system, and pollinators) in Table S5.

DNA Extraction, PCR and Sequencing. We sequenced the plastomes and nuclear ribosomal internal transcribed spacers (ITS) of 27 species. For 13 additional species and 
the outgroup Magnolia grandiflora, the data were downloaded from GenBank. All plant information (voucher, accession numbers) is given in Table S1. When fresh leaf material was available, we performed a chloroplast DNA (cpDNA) enrichment following a protocol (Supplementary Methods 1) adapted from (Napier \& Barnes, 1995; Ostertag, 2014) to obtain sufficient yield with less plant material. For species with only herbarium specimens available or if the protoplast digestion failed (Table S1), we performed genomic DNA extraction on dried leaves using the Macherey Nagel NucleoSpin Plant II kit. All cpDNAenriched and total genomic DNA samples were sent to GATC Biotech (Konstanz, Germany) for paired-end library construction and Illumina HiSeq sequencing.

For the polymorphism study, genomic DNA was extracted from samples of Lamium album, L. galeobdolon, Cardamine amara, and C. impatiens from different German populations. The plastid intergenic regions rpl20-rps12, trnH-psbA, and trnL-trnF + intron of trnL were obtained by PCR following the protocol described in (Schaefer \& Renner, 2010) and Sanger sequencing by GATC (Konstanz, Germany). Sequences available in GenBank for those regions and for the plastid trnS-trnG and the nuclear ITS were added to make the sampling as geographically broad as possible. Voucher information, accession numbers and geographic origin of the plants are provided in Table S7.

Data processing, plastid assembly and annotation. The Illumina raw data, consisting in 125-bp paired-end reads, were quality filtered using FastQC 0.11.3 (Andrews, 2010) and Trimmomatic 0.33 (Bolger et al., 2014), discarding reads with average phred33 score $<20$, and then de novo assembled with ABySS 1.9.0 (Simpson et al., 2009). Plastid contigs were fished using BLASTing (blastn command, (Camacho et al., 2009)) against a database of 698 plastomes available on GenBank. Further read mappings with less stringent parameters and manual inspection were necessary to extend the contigs at the borders of repeats and in low-complexity regions, and to assemble them de novo or based on a closely-related reference (listed in Table S1). These steps were performed using CLC Genomics Workbench 7.0.3 and Geneious R6 (Kearse et al., 2012).

Eight plastomes could be assembled in one circular molecule, and ten additional were recovered at more than $98 \%$ of their length and could also be assembled because they displayed high collinearity with published plastomes of closely-related species. Finally, nine plastomes were only partially recovered, as suggested by the comparison to reference lengths and gene content (Table S1, Fig. S1). Reads were mapped on all full or partial assemblies (Table S1) with BWA (Li \& Durbin, 2009) to generate two consensus for each species. The first "70\%" consensus had bases replaced by IUPAC ambiguities when an alternative base was found in more than $30 \%$ of the reads. The second " $70 \%-5 x$ " consensus was generated from the previous one, but bases with read depth $<5$ were replaced by Ns. The latter consensus was used in further phylogenetic analyses and rate calculations, whereas the $70 \%$ consensus was annotated using the Geneious annotation tool and manual verifications using the online blastn and blastp interfaces of the NCBI website (https://blast.ncbi.nlm.nih.gov/Blast.cgi) as well as the online server of tRNA-scanSE (Lowe \& Eddy, 1997). These 27 plastomes were submitted to GenBank with accession numbers provided in Table S1. Nuclear ITS sequences were obtained from all contig pools using blastn with Corallorhiza macrantha (GenBank accession NC_025660.1) as query.

Phylogenetic analyses. Chloroplast protein coding genes (CDS) and chloroplast noncoding intergenic regions (NCS) were extracted from the 41 plastomes (Table S1). Single regions were aligned separately (i) by quadruplet and (ii) including all quadruplets for which the region was available + Magnolia, using MAFFT (Katoh \& Standley, 2013) in the case of NCS, and MACSE (Ranwez et al., 2011) for CDS, allowing to keep sequences in the 
correct reading frame. Alignments were manually inspected and discarded when they were too difficult to align (mostly in cases of non-coding regions aligned across all quadruplets) or when at least one taxon (in the case of quadruplet alignments) or 20 taxa (in the case of global alignments) were missing. For each quadruplet, all single CDS alignments were then concatenated in a total CDS matrix, and the same was done separately for NCS alignments, resulting in 10 total CDS matrices of four taxa (of 20,883 to 62,325 characters) and 10 total NCS matrices of four taxa (of 11,450 to 41,735 characters). Finally, two global CDS and NCS matrices of 41 taxa and 57,993 and 64,441 characters were obtained by concatenating the single alignments comprising all quadruplets + Magnolia. All singleregions and total matrices were submitted to Maximum Likelihood phylogenetic analyses based on the GTRGAMMA model implemented in RAxML (Stamatakis, 2014), with 100 bootstrap replicates. Single-region trees where compared to the trees obtained from concatenated matrices, and regions supporting with at least $70 \%$ bootstrap support a different topology than the majority where removed from the concatenated matrices for the concerned quadruplets, resulting in two new concatenated CDS and NCS matrices for each quadruplet as well as two new concatenated global CDS and NCS matrices. In addition, eleven matrices consisting of the concatenation of ITS1 and ITS2 were also generated, one for each quadruplet and a global one, and aligned with MAFFT. All concatenated matrices, including the original ones comprising conflicting regions were submitted to phylogenetic inference using MrBayes v. 3.2 (Ronquist et al., 2012) under a GTR + Y model, and performing two runs of 2.5 million generations (to reach convergence). A burnin fraction of $25 \%$ was removed from the sampling before building consensus trees and analyzing posterior distributions of branch lengths (see below). The Bayesian analyses were repeated following best partitioning schemes and substitution models assessed with PartitionFinder v. 1.1.1 (Lanfear et al., 2012). Finally, in order to assess the robustness of our results to an increase of sampling, CDS were also extracted from the plastomes of 358 angiosperms available in GenBank (accessions in Table S7), aligned with the CDS of our study species using MACSE, and then concatenated in a global matrix of 399 taxa and 42,132 characters. This alignment was submitted to phylogenetic Bayesian Inference using Exabayes (Aberer et al., 2014) for two runs of 10 million generations with sampling frequency of 1000 , which was enough to reach convergence. The most important matrices will be made available in Dryad upon acceptance of the manuscript.

\section{Polymorphism analyses}

For the study of polymorphism in Lamium and Cardamine, each region was aligned using MAFFT and differences observed between the two sequences used in our full plastome or ITS comparisons were considered as fixed substitutions if present in all available sequences of the species, and as polymorphic if present in only some of them. Inside one quadruplet (Lamium or Cardamine), the substitutions were polarized based on the two outgroup species, and conservatively, we removed sites for which both states were found in the ingroup and which showed different states in the outgroups.

Testing for Rate Heterogeneity and for Confounding Factors. Tajima's tests (Tajima, 1993) for rate heterogeneity between the SB and NSB species of each quadruplet were performed on all concatenated matrices using MEGA v 7.0 (Kumar et al., 2016), and taking the most closely-related species of each SB/NSB pair as outgroup, except for Campanula, Cardamine and Ranunculus, for which we chose Cirsium vulgare, Geranium palmatum and $R$. repens. The significance level of $\alpha=0.05$ was Bonferroni-corrected to $\alpha_{\text {Bonf }}=0.005$ accounting for ten individual tests that were performed on each sequence data set. For each quadruplet in each Bayesian phylogenetic analysis, the relative substitution rate of SB 
and NSB species was obtained by estimating the post-burnin average length of their branch starting from the most recent common ancestor of both species. We also extracted the $95 \%$ confidence intervals $(\mathrm{Cl})$ of those branch-lengths from the post-burnin tree sample and defined a confidence interval overlap index between the SB and the NSB species to facilitate visualization of the results. This $\mathrm{Cl}$ overlap index is defined as the difference between the lowest bound of the largest mean $\mathrm{BL} 95 \% \mathrm{Cl}$ and the upper bound of the smallest mean BL $95 \% \mathrm{CI}$ normalized by the species pair mean BL. Finally, Jukes-Cantor corrected ratios of non-synonymous to synonymous substitutions (dN/dS) were calculated for each SB and NSB species in the concatenated quadruplet CDS alignments, using SNAP 2.1.1 (Korber, 2000) (www.hiv.lanl.gov).

\section{Results}

\section{High quality plastome data and phylogenies}

We analyse here the full plastome of 41 angiosperm species, of which 27 are generated de novo from species belonging to the genera Campanula (Campanulaceae, Asterales), Cardamine (Brassicaceae, Brassicales), Carex (Cyperaceae, Poales), Cirsium (Asteraceae, Asterales), Galium (Rubiaceae, Gentianales), Geranium (Geraniaceae, Geraniales), Lamium (Lamiaceae, Lamiales), Ranunculus (Ranunculaceae, Ranunculales), Poa (Poaceae, Poales) and Silene (Caryophyllaceae, Caryophyllales). We choose these genera and species because of the available detailed description of the seed-bank status and life history traits (Thompson et al., 1997; Baskin \& Baskin, 2014) (see details in SOM). We develop a new protocol for chloroplast DNA (cpDNA) extraction (SO Methods 1), so that DNA is extracted either 1 ) by enzymatic digestion of fresh leaves followed by cpDNA enrichment (yielding an average per-base read-depths of 209x), 2) directly from fresh leaves (yielding a coverage of 140x), or 3 ) directly from a dry herbarium specimen (yielding a coverage of 173x, Table S1). Regardless of the approach, we obtain an average per-base read depths of 199x (median of 159x) ranging from 13x (Silene uniflora; herbarium material) to $907 x$ (Galeopsis tetrahit; cpDNA enrichment). In 19 of the 27 species, the complete plastid genome could be recovered with a high coverage ( $>100 x$, Table S1).

The quality of our 27 new plastomes and the final coverage depends on the quality of the starting material and the extraction methods. The modified enrichment protocol that we develop here works with a very limited amount of starting material, in contrast to previous work (Kolodner et al., 1976; Bookjans et al., 1984; Palmer, 1986; Jansen et al., 2005). Compared to direct genomic DNA extraction our method yields an average increase in read depth of more than $20 \%$ and up to more than $47 \%$ when excluding species for which senescing/herbivore-damaged leaves or mainly petiole material is used (see Table S1). Intact young leaf material is best for cpDNA enrichment, but the data recovered from direct DNA extraction of 31 to 55 years-old herbarium specimens also allows us to assemble large plastome regions with high coverage.

We find that intra-plastome read depth is heterogeneous across our samples but of sufficient quality for read mapping and substitution calling (Table S1). Out of 27 plastomes we find eight with a sufficient coverage to be completely assembled. Ten other species require a few junctions between non-overlapping contigs via inference of gaps (up to ten gaps) using high collinearity to available references. The cumulated length of these represents between $98 \%$ and $100 \%$ of the reference length suggesting that those plastomes are in fact (almost) complete. Finally, low coverage often combined with the presence of repeated sequences prevent the complete assembly of nine plastomes (Galium odoratum, Campanula sp., Carex sp., and two Geranium species, Table S1). For those nine species, we still recover cumulated lengths between $51 \%$ and $83 \%$ of their 
respective reference lengths with most of the missing nucleotides being non-coding DNA.

The plastomes of all taxa studied here have a conserved gene content with 78 protein-coding genes, four rDNAs and 30 tRNAs present in most lineages (Fig. S1). Some missing genes have a distribution consistent for all species of a genus, suggesting that their absence is not due to gaps in our sequencing but to a loss of function (details in methods). The quadripartite plastome structure consisting in two large (LSC) and small (SSC) single copy regions separated by one inverted repeat (IR), as well as gene collinearity are conserved in most lineages, and thus support the homology of most intergenic regions used in the following phylogenetic analyses. The consistency of results is checked 1) between coding sequences (CDS), non-coding sequences (NCS) and the nuclear ITS locus, 2) between partitioned datasets with different substitution models across genes and non-partitioned datasets, and 3) between datasets where genes producing trees conflicting with the most often recovered topology were removed and datasets where all genes were kept (see methods).

We build a phylogeny of ten angiosperm clades spanning nine orders (listed above) by including quadruplets of species consisting of one with well documented long term persistent seed-bank (hereafter SB), one with a relative absence of seed-bank compared to its sister (NSB), and two outgroups belonging to the same genus or a closely-related one. After controlling for supported incongruences between gene trees (see methods), three times ten local alignments of four taxa and three global alignments of the ten clades are built concatenating separately protein-coding plastid genes (CDS), non-coding plastid (NCS) regions, and nuclear ITS data. We then compute the phylogenetic trees using Bayesian methods and find that all concatenated data sets yield qualitatively identical, wellsupported (most Bayesian posterior probabilities PP = 1), tree topologies (Fig. 1), regardless of species sampling, partitioning, or presence or absence of conflicting regions (Fig. S2, details in methods). The relationships between the families are consistent with those presented by the Angiosperm Phylogeny Group (APGIV, 2016) except for a conflict between the positions of Silene (Caryophyllaceae) as sister to Geraniaceae+Brassicaceae in the non-coding (NCS) trees (Fig. S2c,d), and sister to Asteraceae+Lamiaceae+Rubiaceae in the CDS trees (Fig. 1; Fig. S2a,b), the latter being the position accepted by APGIV (2016). Note that the tree based on the nuclear ITS dataset is less well resolved, with many low-supported (PP $<0.97$ ) clades (Fig. S2e and details of conflicts in SOM). Finally, as intra-generic topologies of Campanula, Cardamine and Ranunculus appear different from initially expected, we redefine outgroups for those genera (see methods).

\section{Seed-banking species have equal or higher substitution rates than non-seed- banking species.}

Based on these phylogenies we obtain the branch length (BL) measures $B L_{S B}$ and $B_{N S B}$ respectively for seed-banking and non-seed-banking species since they diverged from their most-recent common ancestor. Our principal result is that the substitution rate in seed-banking (SB) species is equal or higher than that of non-seed-banking (NSB) species, namely $B L_{S B}>B L_{N S B}$. This result is supported in analyses based on partitioned or nonpartitioned alignments including all regions or only non-conflicting ones (conflicting regions for the phylogeny building), and including all ten clades or only local alignments for quadruplets. All branch lengths for SB and NSB species estimated in the different analyses are reported in Tables S2 and S3.

In Fig. 2, we show the result of the ratio $B L_{S B} / B_{N S B}$ for non-partitioned analyses at the angiosperm level. If seed-banking has no effect on the rate of substitution the ratio $B L_{S B}$ / $B L_{N S B}$ is expected to be one, while most genera show a higher rate of evolution of the 
seed-banking species (Fig. 2). For both plastid CDS and NCS, eight out of ten species pairs display longer branch lengths in the SB than in the NSB species (sign test $p$-value $=$ 0.044), and results are consistent per quadruplet for CDS and NCS. Two exceptions to this consistency are seen with Galium and Ranunculus, while Geranium is the only quadruplet showing $B L_{S B}<B L_{N S B}$ both at CDS and NCS (Fig. 2a,b). Note that in all these cases, the 95 $\%$ confidence interval $(\mathrm{Cl})$ overlap index is always positive, indicating significant differences in substitution rate in all pairs for both CDS and NCS datasets (black rectangles in Fig. $2 a, b)$. Additionally, we perform Bonferroni-corrected Tajima's tests for rate heterogeneity ( $p$ values indicated in Table 1), which shows that four (Campanula, Cirsium, Lamium, and Poa) out of ten species SB/NSB pairs have significantly different substitution rates ( $p$-value $<0.005)$, in a consistent manner between CDS and NCS datasets. The inconsistency observed for Galium and Ranunculus between CDS and NCS in Fig. 2 is resolved in favour of the result at NCS because the p-values from the Tajima's tests and the Cl overlap index are respectively lower and higher for NCS than CDS for both quadruplets. We favour thus $\mathrm{BL}_{S B}>\mathrm{BL}_{\mathrm{NSB}}$ in Galium and $\mathrm{BL}_{\mathrm{SB}}<\mathrm{BL}_{\mathrm{NSB}}$ in Ranunculus (Fig. 2, Table 1). Nuclear ITS data confirm for most quadruplets the higher rate of substitution in seed-banking versus nonseed-banking species (Fig. 2c) although topological conflicts prevent the use of Cardamine and lead us to use genus-level data for Poa (Fig. S2e-g). The only conflicts observed between plastid and ITS results are for Carex and Ranunculus, but these are not supported by $\mathrm{Cl}$ overlap indexes, or by Tajima's test $\mathrm{p}$-values. We thus conclude that both genera follow their plastid global trend, i.e. $B L_{S B}>B_{N S B}$ (Fig. 2 and Table 1). Finally, we confirm our results from Fig. 2 using a phylogenetic tree for only CDS with 399 available taxa from most angiosperm families and orders (Fig. S2h). The results are confirmed for most quadruplets, including Cirsium, Geranium and Cardamine for which a closer outgroup was available in this extended dataset. The only exception is Silene, in which the non-seed-banking $S$. uniflora has a slightly longer branch than the seed-banking $S$. vulgaris (Fig. S2h), a result contradicting those from Fig. 2a (Table S3, Fig. S2a-e).

\section{Life-history traits or selection do not explain the difference in substitution rates}

We control here that the differences we observe between $B L_{S B}$ and $B L_{N S B}$ are not due to confounding life-history traits or differential selection acting on chloroplast genomes. We document for each species pair the estimated relative generation time, location, habitat disturbance or sexual system as potential explanatory factor (Table S5). Location, habitat disturbance or sexual system (Table S5) are widely similar between sister species and thus unlikely to explain the higher substitution rates in SB. There is no significant correlation between BL estimates (or their ratios) and generation time (Fig. 3a, Table S4). Generation time is here fairly heterogeneous and difficult to estimate as most species are perennial. The absence of correlation is chiefly due to the fact that in some cases the SB species has a higher generation time than the NSB, while the reverse is true in other cases. The substitution rate difference cannot be attributed either to the single-species average plastome coverage (Fig. S3a,b). An alternative explanation could be the difference in selective pressure (positive or purifying) acting on chloroplast genomes of seed-banking or non-seed-banking species. However, dN/dS values do not correlate with BL (Fig. 3b), or with relative generation times (Fig. S3c). Interestingly, the $\mathrm{dN} / \mathrm{dS}$ ratios appear similar between sister species but different across genera (Table S6), indicating that the strength of positive or purifying selection is defined rather by genus wide constraints (such as genomic context, habitat or local selective pressure) than at the species specific level or due to SB or NSB traits. 


\section{Polymorphism does not explain the differences in substitution rates}

A final possible explanation for the difference in substitution rate between seedbanking and non-seed-banking species lies in the amount of polymorphism. As SB species may exhibit higher rates of polymorphism than NSB, our substitution rate could be affected by such effect. We thus investigate the relationship between polymorphic sites and substitutions in four plastid intergenic spacers, one plastid intron and the nuclear ITS of SB and NSB species of Lamium and Cardamine (Table 2). Additional sequences from different locations in Germany and abroad (Table S7) reveal that in both lineages the higher number of substitutions in the seed-banking-species (reported in Fig. 2 and Table S3) consists indeed mostly of fixed mutations. Following the theory of storage effect, seed-banking species exhibit nevertheless a higher number of polymorphic sites than non-seed-banking species. In the five plastid regions grouped together, $33 \%$ of observed substitutions in the seed-banking $L$. album are in fact polymorphisms against $8 \%$ in the non-seed-banking $L$. galeobdolon and a similar outcome is found for Cardamine (5\% against $0 \%)$. This is also the case in the nuclear ITS for Cardamine (33\% against $25 \%$ ) but not in Lamium $(0 \%$ against 22\%).

\section{Discussion}

\section{Seed-bankers have equal or higher substitution rates}

Our main result shows that substitution rates in seed-banking species are equal or higher than in species with less persistent seed-banks, as observed for chloroplast genome protein-coding and non-coding sequences and consistently across various groups of angiosperms. The results for the nuclear ITS region are less clear but seem to show a similar trend, which is also supported by the preliminary work of Whittle (Whittle, 2006) on other angiosperm genera. The broad choice of studied genera is possible because we also develop a protocol for chloroplast DNA enrichment for high throughput DNA sequencing. This allows to analyze a unique combination of plastomes from yet unstudied seed-banking and non-seed-banking species from small amount of fresh starting material, including senescent of herbivore-damaged leaves.

The detrimental effect that prolonged seed soil storage may have on DNA integrity (Levin, 1990; Waterworth et al., 2016) is expected to result in generally elevated mutation rates in SB species compared to closely related NSB species. We use here predictions about the molecular clock hypothesis (Zuckerkandl \& Pauling, 1965), stating that the neutral substitution rate is a direct function of the nucleotide mutation rate and does not depend on the species size (Kimura, 1968). Since life histories of our study species are largely identical within SB/NSB pairs (Table S5), the equal or even higher number of substitutions in the SB species stems from the seed-bank. We here therefore reject the alternative hypothesis that mutations do not occur in seeds. In addition, we conclude that the absence of noticeable differences in selection within our species pairs (Table S6) indicates a similar proportion of effectively neutral (or nearly neutral) mutations (Ohta \& Kimura, 1971) in both SB and NSB species. In other words, the proportion and selective coefficients of deleterious mutations arising in the seeds appear to be similar to those of the mutations originating in above-ground plants. The seed-bank acts therefore as source of additional molecular variants whose likelihood of getting fixed in the population is similar to those arising in above-ground plants.

A meta-analysis of 13 studies (Honnay et al., 2008) and studies of genetic diversity in A. thaliana populations in Norway (Lundemo et al., 2009; Falahati-Anbaran et al., 2014) do not show, however, a significant accumulation of rare genotypes in the soil seed-bank. This apparently contradicts the notion of persistent seed-banks as sources of genetic 
variability. We explain these results by a moderate proportion? of new fitness-neutral genotypes which constantly germinate from the seed-bank and homogenize above- and below-ground populations genetically. This is consistent with the fact that disrupted genome integrity with respect to DNA double strand breaks does impair germination in $A$. thaliana, while the effects of moderate chemical mutagenesis are largely tolerated (Waterworth et al., 2010). This suggests first that the majority of persisting seed-bank-borne mutations would thus be neutral or nearly neutral (Ohta \& Kimura, 1971) and the selection against mutant seeds in early life stages (seedling) may be less severe than previously assumed. Second, environmental uncertainties against which seed-banks constitute a bet hedging strategy (Brown \& Venable, 1986; Evans \& Dennehy, 2005) may result during certain periods in stronger random genetic drift due to catastrophic decrease in above-ground population size. This might allow for establishment and propagation of seedlings emerging from mutant seeds that would likely be outcompeted under normal environmental conditions, allowing mutant alleles to rise in frequency. Our results thus call for studies on the natural variation and fitness effect of seed born mutations.

\section{Seed-banking influences micro- and macro-evolutionary studies}

Assuming a neutral model of evolution, the amount of genetic polymorphism and ecological data on the average above-ground population size can be jointly used to infer the persistence of the seed-bank (Tellier et al., 2011) and past demographic events (Živković \& Tellier, 2012). Ignoring the mutation rate in seeds thus yields errors in the estimations of the length of coalescent trees, and as a consequence on the estimation of neutral population parameters such as the effective population size and past demographic history. In addition, with regards to natural selection, seed-banks are also a source of potentially advantageous mutations which increase the adaptive potential of the population, though note that a persistent seed-bank has for effect to slow down the speed of natural selection (Hairston Jr \& De Stasio Jr, 1988; Koopmann et al., 2016) compared to populations with short seed-banks. Finally, when studying the recent divergence between population and/or species, taking into account the adequate rate of mutation (including in seeds) is important to estimate times of splits, as seed-banks tend to decrease differentiation (Vitalis et al., 2004) and increase incomplete lineage sorting. An example of incomplete lineage sorting caused by recent divergence and possible persistent seedbanks can be seen in wild tomato species (Solanum clade, (Pease et al., 2016)).

In phylogenetics substitution rate heterogeneity is well-known to occur not only between and within genes but also between taxa at a given gene, from inter-family to interspecies taxonomic levels (Thomas et al., 2006). The factors generating this heterogeneity can be differences in 1) metabolic rates, 2) life-history such as generation time, and 3) altitude and latitude (Bromham et al., 2015). As it is especially difficult to disentangle the effects of these various factors on substitution rate heterogeneity between lineages, phylogeneticists use models of nucleotide evolution allowing substitution rates to change during the process of cladogenesis and lineage evolution. Most of the models assume rate autocorrelation, that is assume a priori that large jumps of the rate along the phylogeny are less probable than gradual changes (reviewed in (Ho \& Duchêne, 2014)). Geneticallydependent rate heterogeneity is commonly expected to be more autocorrelated than changes in environment-dependent rates. We here suggest that a priori knowledge of lineages with or without long-term seed-banking is extremely useful for phylogeny estimation, for example to further refine models dealing with the molecular dating of angiosperm phylogenies. As a corollary, seed-banking persistency could be predicted for populations exhibiting different rates if other substitution rate-modifying factors can be ruled out. 
A major limitation in studying seed-banking is the availability of reliable data on this trait, especially regarding the absence of seed-banking. Seed-bank persistence is in effect a difficult to measure and gradually expressed trait, and we resort here to comparing closely related species with a pronounced difference in seed-bank longevity. Without the many small-scale ecological studies performed during the last century our analysis would have not been possible (compiled in (Thompson et al., 1997; Baskin \& Baskin, 2014)). Seed-banks are of importance for conservation biology and restauration ecology, and more data on seed longevity and seed-banking in angiosperms are also needed to better understand macro- and micro-evolutionary processes. Our study shows that the seed reservoir is not genetically inert and exhibit new mutations measured here as substitution rates, which should be taken into account in ecological as well as population genetic and phylogenetic analyses.

\section{Acknowledgements}

We thank A. Saatkamp (Aix Marseille University - IMBE, France) for his initial advises and for helping us to access the Thompson database, and $G$. Achaz for comments on the manuscript. AT is supported by the Deutsche Forschungsgemeinschaft grants TE809/1-1, TE809/7-1 and sequencing was funded in part by the Federal Ministry of Education and Research (BMBF, Germany) within the AgroClustEr Synbreed - Synergistic plant and animal breeding (grant 0315528I).

\section{Author Contributions}

MD, SB, HS and AT designed the study and wrote the manuscript. MD and SB performed the analyses, MD and HS collected samples, MD, SS and SB performed the lab work. 


\section{References}

Abdalla F, Roberts E. 1969. The effects of temperature and moisture on the induction of genetic changes in seeds of barley, broad beans, and peas during storage. Annals of Botany 33(1): 153-167.

Aberer AJ, Kobert K, Stamatakis A. 2014. ExaBayes: massively parallel Bayesian tree inference for the whole-genome era. Molecular biology and evolution 31(10): 25532556.

Andrews S. 2010. FastQC: A quality control tool for high throughput sequence data. Reference Source.

Baskin CC, Baskin JM. 2014. Seeds: Ecology, Biogeography, and Evolution of Dormancy and Germination: Academic Press.

Bolger AM, Lohse M, Usadel B. 2014. Trimmomatic: a flexible trimmer for Illumina sequence data. Bioinformatics: btu170.

Bookjans G, Stummann B, Henningsen K. 1984. Preparation of chloroplast DNA from pea plastids isolated in a medium of high ionic strength. Analytical biochemistry 141(1): 244-247.

Bromham L, Hua X, Lanfear R, Cowman PF. 2015. Exploring the relationships between mutation rates, life history, genome size, environment, and species richness in flowering plants. The American Naturalist 185(4): 507-524.

Brown JH, Kodric-Brown A. 1977. Turnover rates in insular biogeography: effect of immigration on extinction. Ecology 58(2): 445-449.

Brown JS, Venable DL. 1986. Evolutionary ecology of seed-bank annuals in temporally varying environments. American Naturalist: 31-47.

Camacho C, Coulouris G, Avagyan V, Ma N, Papadopoulos J, Bealer K, Madden TL. 2009. BLAST+: architecture and applications. BMC bioinformatics 10(1): 1.

Charlesworth B. 1994. Evolution in age-structured populations: Cambridge University Press Cambridge.

Chauhan K, Swaminathan M. 1984. Cytogenetical effects of ageing in seeds. Genetica 64(2): 69-76.

Cheah K, Osborne DJ. 1978. DNA lesions occur with loss of viability in embryos of ageing rye seed. Nature 272(5654): 593-599.

Dandoy E, Schnys R, Deltour R, Verly WG. 1987. Appearance and repair of apurinic/apyrimidinic sites in DNA during early germination of Zea mays. Mutation Research/Fundamental and Molecular Mechanisms of Mutagenesis 181(1): 57-60.

Dourado A, Roberts E. 1984a. Chromosome aberrations induced during storage in barley and pea seeds. Annals of Botany 54(6): 767-779.

Dourado A, Roberts E. 1984b. Phenotypic mutations induced during storage in barley and pea seeds. Annals of Botany 54(6): 781-790.

Evans ME, Dennehy JJ. 2005. Germ banking: bet-hedging and variable release from egg and seed dormancy. The Quarterly Review of Biology 80(4): 431-451.

Falahati-Anbaran M, Lundemo S, Stenøien HK. 2014. Seed dispersal in time can counteract the effect of gene flow between natural populations of Arabidopsis thaliana. New Phytologist 202(3): 1043-1054.

Finch-Savage WE, Leubner-Metzger G. 2006. Seed dormancy and the control of germination. New Phytologist 171(3): 501-523.

Hairston Jr NG, De Stasio Jr BT. 1988. Rate of evolution slowed by a dormant propagule 
pool.

Ho SY, Duchêne S. 2014. Molecular-clock methods for estimating evolutionary rates and timescales. Molecular ecology 23(24): 5947-5965.

Honnay O, Bossuyt B, Jacquemyn H, Shimono A, Uchiyama K. 2008. Can a seed bank maintain the genetic variation in the above ground plant population? Oikos 117(1): $1-5$.

Jansen RK, Raubeson LA, Boore JL, Chumley TW, Haberle RC, Wyman SK, Alverson AJ, Peery R, Herman SJ, Fourcade HM. 2005. Methods for obtaining and analyzing whole chloroplast genome sequences. Methods in enzymology 395: 348384.

Kaj I, Krone SM, Lascoux M. 2001. Coalescent theory for seed bank models. Journal of Applied Probability 38(2): 285-300.

Katoh K, Standley DM. 2013. MAFFT multiple sequence alignment software version 7: improvements in performance and usability. Molecular biology and evolution 30(4): 772-780.

Kearse M, Moir R, Wilson A, Stones-Havas S, Cheung M, Sturrock S, Buxton S, Cooper A, Markowitz S, Duran C. 2012. Geneious Basic: an integrated and extendable desktop software platform for the organization and analysis of sequence data. Bioinformatics 28(12): 1647-1649.

Kimura M. 1968. Evolutionary rate at the molecular level. Nature 217(5129): 624-626.

Kolodner R, Tewari K, Warner R. 1976. Physical studies on the size and structure of the covalently closed circular chloroplast DNA from higher plants. Biochimica et Biophysica Acta (BBA)-Nucleic Acids and Protein Synthesis 447(2): 144-155.

Koopmann B, Mueller J, Tellier A, Živković D. 2016. The Fisher-Wright model with deterministic seed bank and selection. arXiv preprint arXiv:1605.06255.

Korber B 2000. SNAP: Synonymous Non-synonymous Analysis Program.

Kumar S, Stecher G, Tamura K. 2016. MEGA7: Molecular Evolutionary Genetics Analysis version 7.0 for bigger datasets. Molecular biology and evolution: msw054.

Lanfear R, Calcott B, Ho SY, Guindon S. 2012. PartitionFinder: combined selection of partitioning schemes and substitution models for phylogenetic analyses. Molecular biology and evolution 29(6): 1695-1701.

Lanfear R, Welch JJ, Bromham L. 2010. Watching the clock: studying variation in rates of molecular evolution between species. Trends in Ecology \& Evolution 25(9): 495503.

Levin DA. 1990. The seed bank as a source of genetic novelty in plants. American Naturalist: 563-572.

Li H, Durbin R. 2009. Fast and accurate short read alignment with Burrows-Wheeler transform. Bioinformatics 25(14): 1754-1760.

Lowe TM, Eddy SR. 1997. tRNAscan-SE: a program for improved detection of transfer RNA genes in genomic sequence. Nucleic acids research 25(5): 955-964.

Lundemo S, FALAHATI-ANBARAN M, Stenøien HK. 2009. Seed banks cause elevated generation times and effective population sizes of Arabidopsis thaliana in northern Europe. Molecular ecology 18(13): 2798-2811.

Murata M, Tsuchiya T, Roos EE. 1982. Chromosome damage induced by artificial seed aging in barley. II. Types of chromosomal aberrations at first mitosis. Botanical 
Gazette: 111-116.

Napier JA, Barnes SA. 1995. The isolation of intact chloroplasts. Plant Gene Transfer and Expression Protocols: 355-360.

Nunney L. 2002. The effective size of annual plant populations: the interaction of a seed bank with fluctuating population size in maintaining genetic variation. The American Naturalist 160(2): 195-204.

Ohta T, Kimura M. 1971. On the constancy of the evolutionary rate of cistrons. Journal of Molecular Evolution 1(1): 18-25.

Ostertag J. 2014. Studies on regulation of Arabidopsis thaliana fibrillin 1a import into chloroplasts. Bachelor's Thesis, Technical University of Munich.

Pake CE, Venable DL. 1996. Seed banks in desert annuals: implications for persistence and coexistence in variable environments. Ecology 77(5): 1427-1435.

Palmer JD. 1986. Isolation and structural analysis of chloroplast DNA. Methods in enzymology 118: 167-186.

Pease JB, Haak DC, Hahn MW, Moyle LC. 2016. Phylogenomics reveals three sources of adaptive variation during a rapid radiation. PLoS Biol 14(2): e1002379.

Ranwez V, Harispe S, Delsuc F, Douzery EJ. 2011. MACSE: Multiple Alignment of Coding SEquences accounting for frameshifts and stop codons. PLoS One 6(9): e22594.

Ronquist F, Teslenko M, van der Mark P, Ayres DL, Darling A, Höhna S, Larget B, Liu L, Suchard MA, Huelsenbeck JP. 2012. MrBayes 3.2: efficient Bayesian phylogenetic inference and model choice across a large model space. Systematic biology 61(3): 539-542.

Schaefer H, Renner SS. 2010. A three-genome phylogeny of Momordica (Cucurbitaceae) suggests seven returns from dioecy to monoecy and recent long-distance dispersal to Asia. Molecular phylogenetics and evolution 54(2): 553-560.

Simpson JT, Wong K, Jackman SD, Schein JE, Jones SJ, Birol I. 2009. ABySS: a parallel assembler for short read sequence data. Genome research 19(6): 1117-1123.

Stamatakis A. 2014. RAxML version 8: a tool for phylogenetic analysis and post-analysis of large phylogenies. Bioinformatics 30(9): 1312-1313.

Tajima F. 1993. Simple methods for testing the molecular evolutionary clock hypothesis. Genetics 135(2): 599-607.

Tellier A, Brown JK. 2009. The influence of perenniality and seed banks on polymorphism in plant-parasite interactions. The American Naturalist 174(6): 769-779.

Tellier A, Laurent SJ, Lainer H, Pavlidis P, Stephan W. 2011. Inference of seed bank parameters in two wild tomato species using ecological and genetic data. Proceedings of the National Academy of Sciences 108(41): 17052-17057.

Templeton AR, Levin DA. 1979. Evolutionary consequences of seed pools. American Naturalist: 232-249.

Thomas JA, Welch JJ, Woolfit M, Bromham L. 2006. There is no universal molecular clock for invertebrates, but rate variation does not scale with body size. Proceedings of the National Academy of Sciences 103(19): 7366-7371.

Thompson K, Bakker JP, Bekker RM. 1997. The soil seed banks of North West Europe: methodology, density and longevity: Cambridge university press.

Turelli M, Schemske DW, Bierzychudek P. 2001. Stable two-allele polymorphisms 
maintained by fluctuating fitnesses and seed banks: protecting the blues in Linanthus parryae. Evolution 55(7): 1283-1298.

Vitalis R, Glémin S, Olivieri I. 2004. When genes go to sleep: the population genetic consequences of seed dormancy and monocarpic perenniality. The American Naturalist 163(2): 295-311.

Waterworth WM, Footitt S, Bray CM, Finch-Savage WE, West CE. 2016. DNA damage checkpoint kinase ATM regulates germination and maintains genome stability in seeds. Proceedings of the National Academy of Sciences: 201608829.

Waterworth WM, Masnavi G, Bhardwaj RM, Jiang Q, Bray CM, West CE. 2010. A plant DNA ligase is an important determinant of seed longevity. The Plant Journal 63(5): 848-860.

Whittle CA. 2006. The influence of environmental factors, the pollen : ovule ratio and seed bank persistence on molecular evolutionary rates in plants. J Evol Biol 19(1): 302308.

Willis CG, Baskin CC, Baskin JM, Auld JR, Venable DL, Cavender-Bares J, Donohue K, Rubio de Casas R. 2014. The evolution of seed dormancy: environmental cues, evolutionary hubs, and diversification of the seed plants. New Phytologist 203(1): 300-309.

Živković D, Tellier A. 2012. Germ banks affect the inference of past demographic events. Molecular ecology 21(22): 5434-5446.

Zuckerkandl E, Pauling L. 1965. Evolutionary divergence and convergence in proteins. Evolving genes and proteins 97: 97-166. 
bioRxiv preprint doi: https://doi.org/10.1101/156398; this version posted June 27,2017 . The copyright holder for this preprint (which was not certified by peer review) is the author/funder, who has granted bioRxiv a license to display the preprint in perpetuity. It is made available under aCC-BY-NC-ND 4.0 International license.

\section{Figure legends}

Figure 1. Phylogenetic relationships of the 41 species. The tree was inferred from the Bayesian analysis of the concatenated alignment of 73 plastid protein-coding genes (CDS). Posterior probability for all nodes $\geq 0.99$. Brown: seed-banking (SB) species; green: nonseed-banking (NSB) species. On the right side, abbreviations for the respective SB/NSB species pairs.

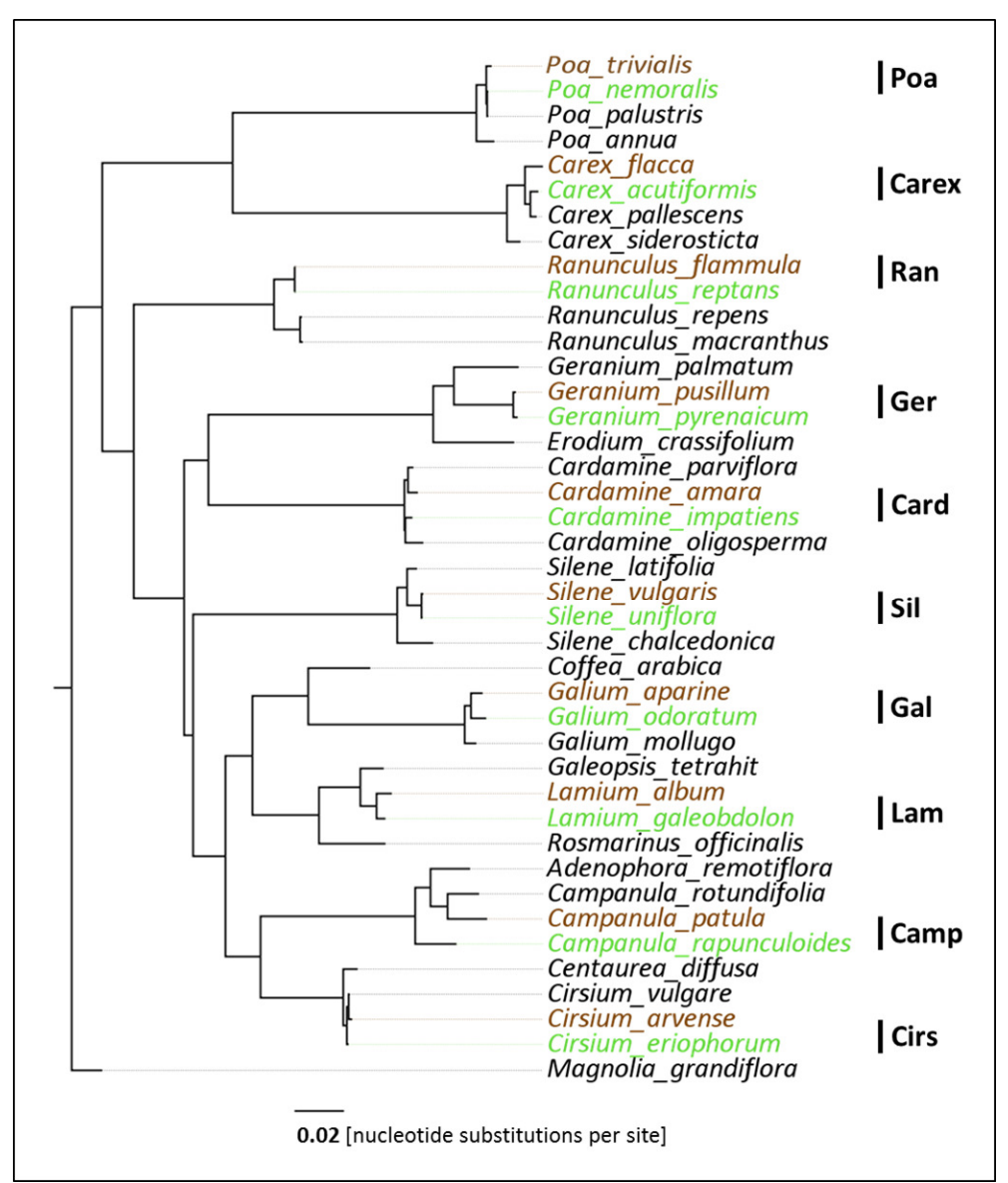


Figure 2. Relative substitution rates of SB/NSB based on branch lengths (BL). (a). Chloroplast coding sequences (CDS), (b). chloroplast non-coding sequences (NCS) and (c). nuclear rDNA ITS sequences. The grey bars indicate the average BL ratios over all post-burnin sampled trees (scaled by primary y-axis). The dashed lines indicate the ratio $\mathrm{BL}_{\mathrm{SB}} / \mathrm{BL}_{\mathrm{NSB}}=1$. The second statistics shown is the $95 \%$ confidence interval $(\mathrm{Cl})$ overlap index, plotted as black bars and with the second $\mathrm{y}$-axis. A positive $\mathrm{Cl}$ overlap index indicates significantly different substitution rates. Data for Cardamine nuclear ITS were not included into the statistic evaluation due to conflicting topology.

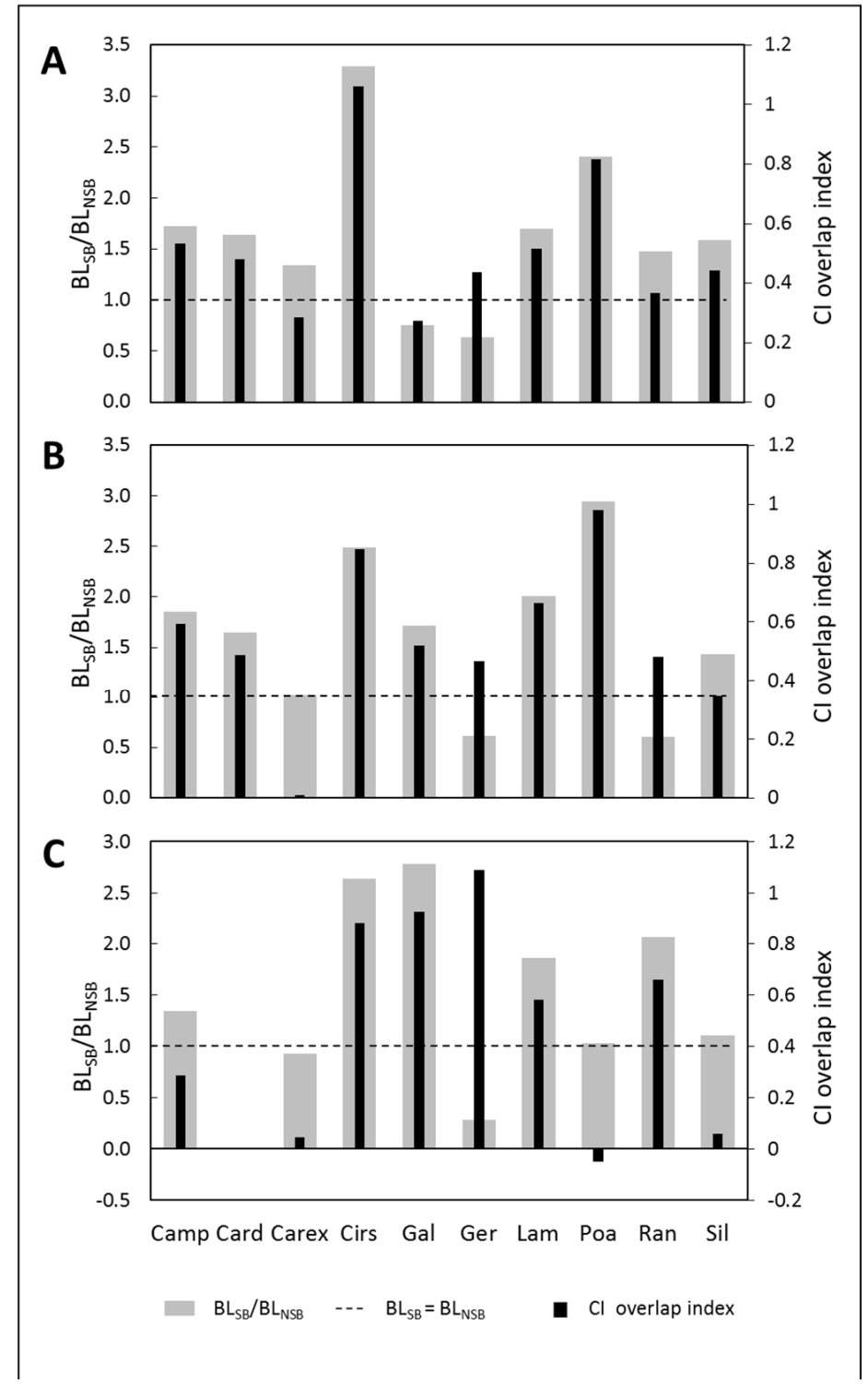


Figure 3. Correlation between substitution rates and additional factors. (a). $\mathrm{BL}_{S B} / \mathrm{BL}_{\mathrm{NSB}}$ ratios as a function of relative generation times of SB and NSB species. (b). Branch length per species $(B L)$ as a function of $d N / d S$ ratio. Data were obtained from nonpartitioned concatenated sequence alignments. P-values given in the inset boxes result from two-tailed t-tests for significant pairwise correlation (see table S4) and relate to CDS (bars), NCS (squares) and ITS (dots) data, respectively.

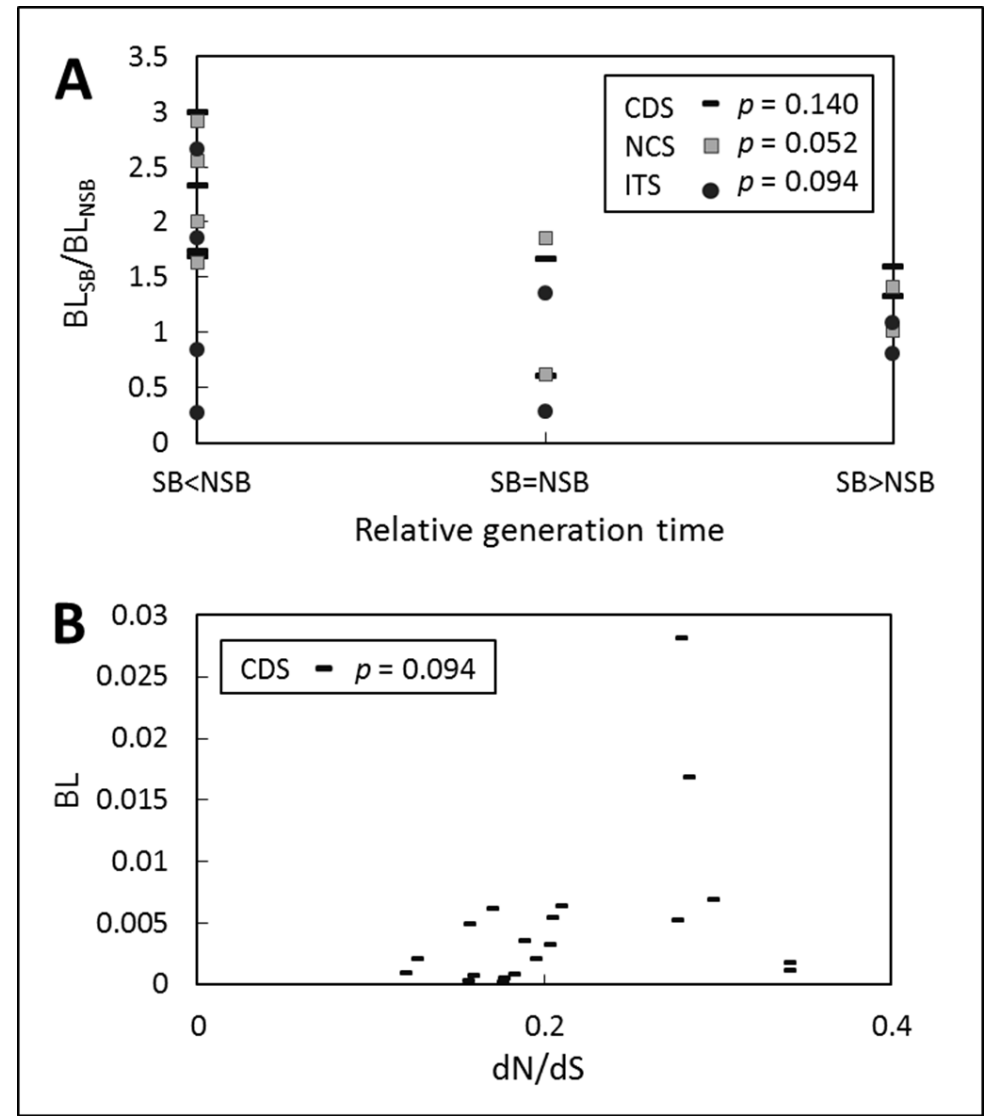


Table 1. P-values of the Tajima's test for rate heterogeneity, in bold when $B L_{S B}$ significantly superior to $\mathrm{BL}_{\mathrm{NSB}}$ after Bonferroni correction. The test was performed on concatenated sequence alignments. For Ranunculus the outgroup species used for ITS ( $R$. venetus) differed from the one used for CDS and NCS (R. repens).

\begin{tabular}{llll} 
& CDS & NCS & ITS \\
\hline Campanula & $\mathbf{0 . 0 0 0}$ & $\mathbf{0 . 0 0 0}$ & 0.104 \\
Cardamine & 0.396 & 0.243 & 0.011 \\
Carex & 0.006 & 0.393 & 0.465 \\
Cirsium & $\mathbf{0 . 0 0 0}$ & $\mathbf{0 . 0 0 0}$ & 0.028 \\
Galium & 0.029 & 0.005 & $\mathbf{0 . 0 0 1}$ \\
Geranium & 0.190 & 0.010 & 0.257 \\
Lamium & $\mathbf{0 . 0 0 0}$ & $\mathbf{0 . 0 0 0}$ & 0.695 \\
Poa & $\mathbf{0 . 0 0 0}$ & $\mathbf{0 . 0 0 0}$ & 0.414 \\
Ranunculus & 0.317 & 0.128 & 0.317 \\
Silene & 0.174 & 0.251 & 1.000 \\
\hline
\end{tabular}

Table 2. Number of substitutions and polymorphisms in plastid and nuclear regions of Lamium and Cardamine. Counts of the number of nucleotides as substitutions ( $F$, fixed) or as polymorphism (P) in the two seed-banking (SB) and non-seed-banking (NSB) species of the given genus.

\begin{tabular}{|c|c|c|c|c|c|c|c|c|c|}
\hline & \multirow{2}{*}{$\begin{array}{c}\text { Length in bp } \\
\text { Lamium / } \\
\text { Cardamine }\end{array}$} & \multicolumn{2}{|c|}{$\begin{array}{l}\text { L. } \\
\text { album } \\
\text { (SB) }\end{array}$} & \multicolumn{2}{|c|}{$\begin{array}{c}\text { L. } \\
\text { galeobdolon } \\
\text { (NSB) }\end{array}$} & \multicolumn{2}{|c|}{$\begin{array}{l}\text { C. amara } \\
\text { (SB) }\end{array}$} & \multicolumn{2}{|c|}{$\begin{array}{c}C . \\
\text { impatiens } \\
\text { (NSB) }\end{array}$} \\
\hline & & $F$ & $\mathbf{P}$ & $\mathbf{F}$ & $\mathbf{P}$ & $\mathbf{F}$ & $\mathbf{P}$ & $F$ & $\mathbf{P}$ \\
\hline Plastome & 2068 / 1638 & 16 & 8 & 12 & 1 & 20 & 1 & 6 & 0 \\
\hline $\begin{array}{l}\text { Nuclear } \\
\text { ITS }\end{array}$ & 448 / 453 & 16 & 0 & 7 & 2 & 2 & 1 & 6 & 2 \\
\hline
\end{tabular}




\section{Supporting Information}

Mutation rates in seeds and seed-banking influence substitution rates across the angiosperm phylogeny

Marcel Dann, Sidonie Bellot, Sylwia Schepella, Hanno Schaefer, Aurélien Tellier

The following Supporting Information is available for this article:

Methods S1: Chloroplast (cp) DNA enrichment protocol.

Text S1. Evidence SB/NSB annotations and expected candidate species clade topologies.

Table S4. Summary of correlation analyses between BL and additional factors.

Table S6. Estimate of natural selection acting on protein-coding chloroplast genes.

Figures S1, S2. attached as pdf

Table S3. Correlation analyses of substitution rates as a function of additional factors

Tables S1-S3, S5, S7. attached as excel files. 


\section{METHODS S1: Chloroplast (cp) DNA enrichment protocol.}

From 0.26 to $3.10 \mathrm{~g}$ fresh leaf material was harvested from living plants preferring the youngest leaves available. Leaves were cleaned with de-ionized water thoroughly and cut into pieces with a razor blade inside a $9 \mathrm{~cm}$ petri dish. Leaf fragments were covered with $15 \mathrm{ml}$ enzyme solution immediately (see Tables below for the composition of all solutions and description of the equipment), making sure all fragments were coated with liquid completely. Petri dishes were sealed with laboratory film and placed on a rotary plate (Orbit LS, Labnet) at $60 \mathrm{rpm}$ at room temperature $\left(\sim 22^{\circ} \mathrm{C}\right)$ for 4 hours.

In principle, chloroplast isolation from protoplasts was achieved as described by Napier and Barnes (1995). Protoplasts were collected by passing the leaf + enzyme solution through a nylon net (pore size $140 \mu \mathrm{m}$ ) and flushing the petri dish with $10 \mathrm{ml}$ cold WIMK. The filter was flushed with another 10 $\mathrm{ml}$ cold WIMK to minimize protoplast loss.

The protoplast solution was collected in $50 \mathrm{ml}$ falcon tubes and centrifuged at $4{ }^{\circ} \mathrm{C}$ and $3988 \mathrm{rcf}$ for 5 min in a SIGMA 2-16K refrigerated centrifuge (SIGMA Laborzentrifugen $\mathrm{GmbH}$ ). The supernatant was discarded and protoplasts were re-suspended in $10 \mathrm{ml}$ cold WIMK. The suspension was centrifuged at $4{ }^{\circ} \mathrm{C}$ and $3988 \mathrm{rcf}$ for $5 \mathrm{~min}$ in a swing-out rotor and the supernatant discarded. Protoplasts were re-suspended in $1.5 \mathrm{ml}$ cold GRM and transferred into $2 \mathrm{ml}$ reaction tubes.

To fragment intact protoplasts, the solution was drawn up in a $5 \mathrm{ml}$ syringe through a $0.45 \mathrm{~mm}$ cannula and re-ejected eight to twelve times. The solution of fragmented protoplasts was put onto an ice-cooled $40 \%$ / $80 \%$ Percoll $^{\circledR}$-in-GRM step gradient. Percoll ${ }^{\circledR}$ gradients were prepared in $15 \mathrm{ml}$ falcon tubes by carefully placing $2 \mathrm{ml}$ of $80 \%$ Percoll $^{\circledR}$ suspension under $4.5 \mathrm{ml}$ of $40 \%$ Percoll $^{\circledast}$ suspension with a Pasteur pipette. After centrifugation for $20 \mathrm{~min}$ at $4{ }^{\circ} \mathrm{C}$ and $3988 \mathrm{rcf}$ in a swing-out rotor the supernatant was removed using a $1 \mathrm{ml}$ pipette. Intact chloroplasts were collected from the 40-80 \% interface with a Pasteur pipette avoiding uptake of the $80 \%$ phase. The chloroplast fraction was split into aliquots of a maximum $750 \mu \mathrm{l}$ and transferred into $2 \mathrm{ml}$ test tubes, which were then filled up to $2 \mathrm{ml}$ with cold GRM. The solution was mixed thoroughly and centrifuged at $2000 \mathrm{rcf}$ for 5 min in a benchtop centrifuge (Centrifuge 5424, Eppendorf AG). The supernatant was removed and the pellet was re-suspended in $0.5 \mathrm{ml}$ cold GRM and chloroplasts were pelleted at $2000 \mathrm{rcf}$ for $5 \mathrm{~min}$ in a benchtop centrifuge.

Finally, cpDNA extraction was performed with the Macherey Nagel NucleoSpin Plant II kit following the manufacturer's suggested protocol, using the chloroplast pellet as starting material.

Solutions, chemicals and enzymes used for chloroplast enrichment:

\begin{tabular}{lllll} 
Solution & Ingredients & Final Concentration & Product ID & Company \\
\hline Enzyme Solution & D-Mannitol & $400 \mathrm{mM}$ & 4175.1 & Carl Roth \\
& $\mathrm{CaCl}_{2}$ anhydr. & $8 \mathrm{mM}$ & $\mathrm{CN} 93.3$ & Carl Roth \\
& $\mathrm{MES}$ & $5 \mathrm{mM}$ & 4256.2 & Carl Roth \\
& Cellulase & $1 \% \mathrm{w} / \mathrm{V}$ & $\mathrm{C} 1184$ & Sigma-Aldrich \\
& Pectinase & $0.25 \% \mathrm{w} / \mathrm{v}$ & 17389 & Sigma-Aldrich \\
& $\mathrm{BSA}$ & $0.1 \% \mathrm{w} / \mathrm{v}$ & 0052.1 & Carl Roth \\
\hline WIMK & D-Mannitol & $500 \mathrm{mM}$ & 4175.1 & Carl Roth \\
& $\mathrm{MES}$ & $5 \mathrm{mM}$ & 4256.2 & Carl Roth \\
\hline GRM & $\mathrm{D}-\mathrm{Sorbitol}$ & $330 \mathrm{mM}$ & 6213.1 & Carl Roth \\
(Grinding Medium) & $\mathrm{HEPES}$ & $50 \mathrm{mM}$ & HN78.1 & Carl Roth \\
& EDTA & $2 \mathrm{mM}$ & CN06.3 & Carl Roth \\
& $\mathrm{MgCl}_{2}$ anhydr. & $2 \mathrm{mM}$ & KK36.1 & Carl Roth \\
& $\mathrm{MnCl}_{2}{ }^{*}\left(\mathrm{H}_{2} \mathrm{O}\right)_{4}$ & $1 \mathrm{mM}$ & T881.3 & Carl Roth \\
\hline
\end{tabular}


bioRxiv preprint doi: https://doi.org/10.1101/156398; this version posted June 27,2017 . The copyright holder for this preprint (which was not certified by peer review) is the author/funder, who has granted bioRxiv a license to display the preprint in perpetuity. It is made available under aCC-BY-NC-ND 4.0 International license.

\section{TEXT S1: Evidence SB/NSB annotations and expected candidate species clade topologies}

\section{Expected clade topologies}

Extended clade tree topologies (original SB/NSB/outgroup 1 plus outgroup 2 obtained from GenBank) according to published phylogenies.

\section{Comparative seed bank persistence}

Candidate species seed banking properties were compared based on two literature-derived parameters: 1) the seed longevity index, which is defined as ratio of $\mathrm{N}[\mathrm{STP}+\mathrm{LTP}] / \mathrm{N}[$ transient+STP+LTP] seed banking records (1), and 2) the proportion of LTP seed banking records (i.e. N[LTP]/N[transient+STP+LTP] records). Both indices were calculated based on the Thompson data base entries (2) and their respective numerical values are listed in table S3. Seed banking properties of species (-pairs) for which these parameters proved ambivalent and did not allow for clear SB/NSB assignments are presented in more detail below.

\section{Campanula}

Expected topology: (((C. patula, C. rapunculus) C. rotundifolia) Adenophora spec.) (3)

\section{Campanula rapunculoides}

Few records exist for $C$. rapunculoides seed banking traits. Thompson et al. (1997) gathered two records implying a transient or short term persistent seed bank, respectively. A more recent study confirmed short term seed bank persistence with documented buried seed longevity for $\leq 3$ years (4). Moreover the existence of tuberoid storage organs implies reliance onto another form of bethedging against spatio-temporal habitat variability, which was found to correlate negatively with soil seed bank persistence ((5) and references within). Thus $C$. rapunculoides can be assumed to be a relatively weak seed banker when compared to $C$. patula (33\% LTP; $50 \%$ persistent records) and $C$. rotundifolia (4 \% LTP; $22 \%$ persistent records; see (2)).

\section{Cardamine}

Expected topology 1: (((C. amara, C. oligosperma) C. parviflora) C. impatiens) (6) Expected topology 2: (((C. amara, C. parviflora) C. oligosperma) C. impatiens) (6)

\section{Cardamine impatiens}

To us no recent records of $C$. impatiens seed bank persistence are known. Thompson et al. (2) list one transient and one short term persistent record, respectively. Additional indication of $C$. impatiens being a transient/short term seed banker are provided by observations of high seed density in the soil $(7,8)$ while population density was observed to be considerably fluctuant among years $(9)$. 
bioRxiv preprint doi: https://doi.org/10.1101/156398; this version posted June 27,2017 . The copyright holder for this preprint (which was not certified by peer review) is the author/funder, who has granted bioRxiv a license to display the preprint in perpetuity. It is made available under aCC-BY-NC-ND 4.0 International license.

\section{Carex}

Expected topology: ((C. acutiformis, C. pallescens) C. flacca) C. siderosticta ? $(10,11)$

\section{Carex acutiformis}

While most sedges are considered (long term) persistent seed bankers, ecological data available makes $C$. acutiformis appear as an exception. Several records confirm frequent occurrence in aboveground vegetation while soil seed bank density is low (12) or empty $(13,14)$. In general seed bank density was observed to be relatively low when compared to other sedges (reviewed in (12)). In fact, to our knowledge, there is but one record of $C$. acutiformis seeds staying viable for $>15-20$ years; the seven remaining records summarised by Thompson et al. (2) imply transient to short term persistent seed banking. The original paper (...) documenting such long seed longevity is not available to us, however. More recent records postdating the Thompson et al. database release confirm the short term persistence of $C$. acutiformis seed banks (15) and imply reliance on clonal growth rather than sexual reproduction $(12,16)$. In more recent studies seed output was shown to be low and germination from seeds could not be observed at all (17). Schütz (15) observed low viable seed bank formation ( $>90 \%$ of buried seeds dead or fatally germinated) under conditions favourable for germination and near-complete germination of surface-sown seeds within 1 year, while germination rates were very low under non-favourable conditions $(15,18)$. In field studies the germination rate was found to be rather low in general as well (16). While Schütz concluded from that that "the ability to form long-persistent seed banks is obvious", rapid loss of $C$. acutiformis seed viability (19) and the overall low seed output make the formation of an effective, long term persistent seed bank appear unlikely. Moreover in recent publications it has become common practice to categorize $C$. acutiformis as transient (20) or short term persistent seed banker (21-23).

\section{Carex flacca}

Carex flacca has been found to produce a high number of seeds resulting in high seed bank densities $(4,24)$ and could be shown to form a LTP seed bank repeatedly (> 20 yrs listed by Thompson et al.(2), $>39 \mathrm{yrs}(25))$ and is accepted as a LTP seed banker (26).

\section{Cirsium}

Expected topology*: ((C. eriophorum, C. vulgare) C. arvense) Centaurea spec.) (27)

* derived from morphological and life history data! 
bioRxiv preprint doi: https://doi.org/10.1101/156398; this version posted June 27,2017 . The copyright holder for this preprint (which was not certified by peer review) is the author/funder, who has granted bioRxiv a license to display the preprint in perpetuity. It is made available under aCC-BY-NC-ND 4.0 International license.

\section{Galium}

Expected topology: (((G. aparine, G. odoratum) G. mollugo) Coffea spec.) (28)

\section{Galium aparine}

Galium aparine does not tend to form a long term persistent seed bank sensu Thompson on a regular basis, but short term soil seed bank persistence up to 5 years has frequently been reported (2). Considerable seed incorporation into deeper soil layers and a resulting delay in seed germination for several seasons has been observed for this species (29-31). In addition maximum seed longevity of 78 years for soil surface storage has been reported (32) (cited in (30)). Hence Galium aparine can legitimately be labelled as seed banking species when compared to Galium odoratum.

\section{Galium odoratum}

Galium odoratum has consistently been found to be a transient seed banker sensu Thompson $(2,33)$. Seed germination itself could rarely be observed (34) and despite being frequent in the aboveground vegetation absence from the soil seed bank has been reported repeatedly $(29,35)$. Reproduction was found to be mainly vegetative and seed production dispersal to be rather poor $(33,36)$. Taken together the available evidence leaves little doubt about Galium odoratum forming a strictly transient seed bank, if any.

\section{Geranium}

Expected topology: (((G. pusillum, G. pyrenaicum) G. palmatum) Erodium spec.) (37)

\section{Geranium pyrenaicum}

Few records on seed bank persistence are available for Geranium pyrenaicum. Transience (3-12 months (38)) and short term persistence ( $\leq 4$ years (2)) have been reported once, respectively. However, additional ecological data suggests Geranium pyrenaicum not to be a long term seed banking species. First of all low seed density in soil has been reported (39). Germination requirements have been found to be very unspecific (40), while average germination rate has been found to be close to unity $(94 \%(41))$. Finally $G$. pyrenaicum has been found to rather match the profile of a $K$-strategist, while $G$. pusillum represents an $r$-strategist (42). This annotation implies $G$. pusillum to form a more pronounced and persistent seed bank when compared to $G$. pyrenaicum (43).

\section{Lamium}

Expected topology: (((L. album, L. galeobdolon) Galeopsis spec.) Rosmarinus spec.) (44) 
bioRxiv preprint doi: https://doi.org/10.1101/156398; this version posted June 27,2017 . The copyright holder for this preprint (which was

not certified by peer review) is the author/funder, who has granted bioRxiv a license to display the preprint in perpetuity. It is made available under aCC-BY-NC-ND 4.0 International license.

\section{Poa}

Expected topology: (((P. nemoralis, P. palustris) P. trivialis) P. annua) (45)

\section{Ranunculus}

Expected topology: ((R. flammula, R. reptans) R. repens)

R. macranthus ? $(46,47)$

\section{Ranunculus reptans}

Seed bank persistence records for $R$. reptans are scarce, corresponding to the species rarity. One record listed by Thompson et al. (2) suggests short term persistence. A more recent observation implies $R$. reptans not to from a soil seed bank that buffers the population from environmental hazards (48). $R$. reptans seems to rely primarily on clonal reproduction $(49,50)$, which is suggested to be owed to self-incompatibility and vegetation periods too short for successful fruiting and seed set $(51,52)$. Hence we labelled $R$. reptans as a non-seed banking species in this study, contrasted by $R$. flammula for which long term persistent seed banking records are abundant (2).

\section{Silene}

Expected topology: ((S. uniflora, S. vulgaris) S. latifolia)

S. chalcedonica ? (53)

\section{Silene uniflora}

To our knowledge no explicit seed bank persistence records are available for Silene uniflora. In one study conducted S. uniflora, while present aboveground, was found absent from the soil seed bank (54). In addition ecological data suggests $S$. uniflora to be a non-seed banking species. Average seed production was reported to be very low while seed predation is prevalent (55), suggesting little capacity to form large seed banks. Moreover seed germination time polymorphism was reported among but not within maternal families $(56,57)$, implying $S$. uniflora doesn't rely on a soil seed bank for bet hedging against environmental uncertainties (58). Finally populations reportedly grow on very shallow and poor substrate (59), indicating particularly bad abiotic conditions for soil seed bank formation. 


\section{References}

1. Thompson K, Bakker JP, Bekker RM, \& Hodgson JG (1998) Ecological correlates of seed persistence in soil in the north-west European flora. Journal of Ecology 86(1):163-169.

2. Thompson K, Bakker JP, \& Bekker RM (1997) The soil seed banks of North West Europe: methodology, density and longevity (Cambridge university press).

3. Cano-Maqueda J, Talavera S, Arista M, \& Catalán P (2008) Speciation and biogeographical history of the Campanula lusitanica complex (Campanulaceae) in the Western Mediterranean region. Taxon 57(4):1252-1252.

4. Czarnecka J (2004) Seed longevity and recruitment of seedlings in xerothermic grassland. Polish Journal of Ecology 52(4):505-521.

5. Saatkamp A, Poschlod P, Venable D, \& Gallagher R (2014) The functional role of soil seed banks in natural communities. Seeds: the ecology of regeneration in plant communities (Ed. 3):263-295.

6. Lihová J, Marhold K, Kudoh H, \& Koch MA (2006) Worldwide phylogeny and biogeography of Cardamine flexuosa (Brassicaceae) and its relatives. American Journal of Botany 93(8):12061221.

7. Esmailzadeh O, Hosseini S, \& Tabari M (2011) Relationship between soil seed bank and above-ground vegetation of a mixed-deciduous temperate forest in northern Iran. Journal of Agricultural Science and Technology 13:399-409.

8. Esmailzadeh O, Hosseini SM, Tabari M, Baskin CC, \& Asadi H (2011) Persistent soil seed banks and floristic diversity in Fagus orientalis forest communities in the Hyrcanian vegetation region of Iran. Flora-Morphology, Distribution, Functional Ecology of Plants 206(4):365-372.

9. Williams $L$ (2000) Annual variations in the size of a population of Cardamine impatiens $L$. WATSONIA-KINGS LYNN-BOTANICAL SOCIETY OF THE BRITISH ISLES- 23(1):209-212.

10. Hendrichs M, Oberwinkler F, Begerow D, \& Bauer R (2004) Carex, subgenus Carex (Cyperaceae)-A phylogenetic approach using ITS sequences. Plant Systematics and Evolution 246(1-2):89-107.

11. Roalson EH, Columbus JT, \& Friar EA (2001) Phylogenetic relationships in Cariceae (Cyperaceae) based on ITS ( $n$ rDNA) and trnT-LF (cpDNA) region sequences: assessment of subgeneric and sectional relationships in Carex with emphasis on section Acrocystis. Systematic Botany:318-341.

12. Leck MA \& Schütz W (2005) Regeneration of Cyperaceae, with particular reference to seed ecology and seed banks. Perspectives in Plant Ecology, Evolution and Systematics 7(2):95133.

13. Van der Valk A \& Verhoeven J (1988) Potential role of seed banks and understory species in restoring quaking fens from floating forests. Vegetatio 76(1-2):3-13.

14. Falińska K (1999) Seed bank dynamics in abandoned meadows during a 20-year period in the Białowieża National Park. Journal of Ecology 87(3):461-475.

15. Schütz W (1998) Seed dormancy cycles and germination phenologies in sedges (Carex) from various habitats. Wetlands 18(2):288-297.

16. Roth S, Seeger T, Poschlod P, Pfadenhauer J, \& Succow M (1999) Establishment of helophytes in the course of fen restoration. Applied Vegetation Science 2(1):131-136.

17. Rasran L, Vogt K, \& Jensen K (2006) Seed content and conservation evaluation of hay material of fen grasslands. Journal for Nature Conservation 14(1):34-45.

18. Schütz W \& Rave G (1999) The effect of cold stratification and light on the seed germination of temperate sedges (Carex) from various habitats and implications for regenerative strategies. Plant Ecology 144(2):215-230.

19. Bekker R, Knevel I, Tallowin J, Troost E, \& Bakker J (1998) Soil nutrient input effects on seed longevity: a burial experiment with fen-meadow species. Functional Ecology 12(4):673-682.

20. Weyembergh G, Godefroid S, \& Koedam N (2004) Restoration of a small-scale forest wetland in a Belgian nature reserve: a discussion of factors determining wetland vegetation establishment. Aquatic conservation: marine and freshwater ecosystems 14(4):381-394. 
21. Donath TW, Holzel N, \& Otte A (2003) The impact of site conditions and seed dispersal on restoration success in alluvial meadows. Applied vegetation science 6(1):13-22.

22. Bissels S, Hölzel N, Donath TW, \& Otte A (2004) Evaluation of restoration success in alluvial grasslands under contrasting flooding regimes. Biological Conservation 118(5):641-650.

23. Török P, Matus G, Papp M, \& Tóthmérész B (2009) Seed bank and vegetation development of sandy grasslands after goose breeding. Folia Geobotanica 44(1):31-46.

24. Czarnecka J (2005) Seed dispersal effectiveness in three adjacent plant communities: xerothermic grassland, brushwood and woodland. Annales Botanici Fennici, (JSTOR), pp 161171.

25. Bekker R, Lammerts E, Schutter A, \& Grootjans A (1999) Vegetation development in dune slacks: the role of persistent seed banks. Journal of Vegetation Science 10(5):745-754.

26. Davies A \& Waite $S$ (1998) The persistence of calcareous grassland species in the soil seed bank under developing and established scrub. Plant Ecology 136(1):27-39.

27. Tofts R \& Silvertown J (2000) Niche differences and their relation to species' traits inCirsium vulgare andCirsium eriophorum. Folia Geobotanica 35(3):231-240.

28. Soza V (2010) Diversification of Galium within Tribe Rubieae (Rubiaceae): Evolution of Breeding Systems, Species Complexes, and Gene Duplication. (International Association for Plant Taxonomy; Botanical Society of America).

29. Thompson K, et al. (2001) Seed size, shape and persistence in the soil in an Iranian flora. Seed Science Research 11(4):345-356.

30. Mennan H (2003) The effects of depth and duration of burial on seasonal germination, dormancy and viability of Galium aparine and Bifora radians seeds. Journal of agronomy and crop science 189(5):304-309.

31. Mennan H \& Ngouajio M (2006) Seasonal cycles in germination and seedling emergence of summer and winter populations of catchweed bedstraw (Galium aparine) and wild mustard (Brassica kaber). Weed Science 54(1):114-120.

32. Özer Z (1972) Yabancı otların yaşam süreleri. Atatürk Üniversitesi ziraat fakültesi dergisi 2:159-163.

33. Kolb A \& Lindhorst S (2006) Forest fragmentation and plant reproductive success: a case study in four perennial herbs. Plant Ecology 185(2):209-220.

34. Donath TW \& Eckstein RL (2008) Grass and oak litter exert different effects on seedling emergence of herbaceous perennials from grasslands and woodlands. Journal of Ecology 96(2):272-280.

35. Kipfer T \& Bosshard A (2007) Geringe Samenbank von beweidbaren Arten für die Etablierung von Waldweiden im Schweizer Mittelland. Botanica Helvetica 117(2):159-167.

36. Ziegenhagen B, et al. (2003) Spatial patterns of maternal lineages and clones of Galium odoratum in a large ancient woodland: inferences about seedling recruitment. Journal of Ecology 91(4):578-586.

37. Fiz O, et al. (2008) Phylogeny and historical biogeography of Geraniaceae in relation to climate changes and pollination ecology. Systematic Botany 33(2):326-342.

38. Roberts H \& BODDRELL JE (1985) Seed survival and seasonal emergence in some species of Geranium, Ranunculus and Rumex. Annals of Applied Biology 107(2):231-238.

39. Richner NA (2014) Changes in arable weed communities over the last 100 years.).

40. Del Fabbro C, Güsewell S, \& Prati D (2014) Allelopathic effects of three plant invaders on germination of native species: a field study. Biological Invasions 16(5):1035-1042.

41. Moravcova L, Pyšek P, Jarošík V, Havlíčková V, \& Zákravský P (2010) Reproductive characteristics of neophytes in the Czech Republic: traits of invasive and non-invasive species. Preslia 82(4):365-390.

42. Schmidt W (1987) Zur Strategie ausgewählter Geranium-Arten - Anpassungen an moderne Bewirtschaftungsmethoden im Weinbau. Dipl.arb. Freiburg i.Br.

43. de Jong T \& Klinkhamer P (2005) Evolutionary ecology of plant reproductive strategies (Cambridge University Press). 
bioRxiv preprint doi: https://doi.org/10.1101/156398; this version posted June 27, 2017. The copyright holder for this preprint (which was not certified by peer review) is the author/funder, who has granted bioRxiv a license to display the preprint in perpetuity. It is made available under aCC-BY-NC-ND 4.0 International license.

44. Bendiksby M, Brysting AK, Thorbek L, Gussarova G, \& Ryding O (2011) Molecular phylogeny and taxonomy of the genus Lamium L.(Lamiaceae): Disentangling origins of presumed allotetraploids. Taxon 60(4):986-1000.

45. Gillespie LJ \& Soreng RJ (2005) A phylogenetic analysis of the bluegrass genus Poa based on cpDNA restriction site data. Systematic Botany 30(1):84-105.

46. Emadzade K, Gehrke B, Linder HP, \& Hörandl E (2011) The biogeographical history of the cosmopolitan genus Ranunculus L.(Ranunculaceae) in the temperate to meridional zones. Molecular Phylogenetics and Evolution 58(1):4-21.

47. Hörandl E, et al. (2005) Phylogenetic relationships and evolutionary traits in Ranunculus sl (Ranunculaceae) inferred from ITS sequence analysis. Molecular phylogenetics and evolution 36(2):305-327.

48. Odland A \& Del Moral R (2002) Thirteen years of wetland vegetation succession following a permanent drawdown, Myrkdalen Lake, Norway. Plant Ecology 162(2):185-198.

49. Fischer M, et al. (2000) RAPD variation among and within small and large populations of the rare clonal plant Ranunculus reptans (Ranunculaceae). American Journal of Botany 87(8):1128-1137.

50. Prati D \& Schmid B (2000) Genetic differentiation of life-history traits within populations of the clonal plant Ranunculus reptans. Oikos 90(3):442-456.

51. Prati D \& Peintinger M (2000) Biological flora of central Europe: Ranunculus reptans L. Flora (Germany) 195(2):135-145.

52. Willi Y \& Fischer M (2005) Genetic rescue in interconnected populations of small and large size of the self-incompatible Ranunculus reptans. Heredity 95(6):437-443.

53. Sloan DB, Oxelman B, Rautenberg A, \& Taylor DR (2010) Phylogenetic analysis of mitochondrial substitution rate variation in the angiosperm tribe Sileneae. BMC Evolutionary Biology 10(1):1.

54. Marteinsdóttir B, Svavarsdóttir K, \& Thórhallsdóttir TE (2010) Development of vegetation patterns in early primary succession. Journal of Vegetation Science 21(3):531-540.

55. Pettersson MW (1994) Large plant size counteracts early seed predation during the extended flowering season of a Silene uniflora (Caryophyllaceae) population. Ecography 17(3):264-271.

56. Prentice HC \& Giles BE (1993) Genetic determination of isozyme variation in the bladder campions, Silene uniflora and S. vulgaris. Hereditas 118(3):217-227.

57. Runyeon H \& Prentice HC (1997) Patterns of seed polymorphism and allozyme variation in the bladder campions, Silene vulgaris and Silene uniflora (Caryophyllaceae). Canadian journal of botany 75(11):1868-1886.

58. Evans ME \& Dennehy JJ (2005) Germ banking: bet-hedging and variable release from egg and seed dormancy. The Quarterly Review of Biology 80(4):431-451.

59. Runyeon H \& Prentice HC (1996) Genetic structure in the species-pair Silene vulgaris and S. uniflora (Caryophyllaceae) on the Baltic island of Öland. Ecography 19(2):181-193. 
Table S4. Summary of correlation analyses between BL and additional factors. The correlations coefficients from Figure S3 are given here. Pearson's correlation coefficients, sample sizes and degrees of freedom are indicated as $r, \mathrm{~N}$ and $\mathrm{df}$, respectively. T-statistics and $p$-values correspond to two-sided t-tests for significant correlation.

\begin{tabular}{|c|c|c|c|c|c|c|c|}
\hline Fig. & Correlation & $\begin{array}{l}\text { Data } \\
\text { Set }\end{array}$ & $r$ & $\mathbf{N}$ & $d f$ & $t$ - statistic & $p$-value \\
\hline \multirow[t]{3}{*}{$3 A$} & relative generation time: & CDS & -0.541 & 8 & 6 & -1.702 & 0.140 \\
\hline & $B L_{S B} / B L_{N S B}$ ratio & NCS & -0.675 & 8 & 6 & -2.421 & 0.052 \\
\hline & & ITS & -0.288 & 8 & 6 & -0.797 & 0.456 \\
\hline \multirow[t]{2}{*}{ 3B } & $\mathrm{dN} / \mathrm{dS}$ value : & CDS & 0.384 & 20 & 18 & 1.765 & 0.094 \\
\hline & BL for individual species & & & & & & \\
\hline \multirow[t]{3}{*}{ S3A } & species pair average & CDS & -0.486 & 10 & 8 & -1.571 & 0.155 \\
\hline & plastome coverage : & NCS & -0.460 & 10 & 8 & -1.465 & 0.181 \\
\hline & $\mathrm{BL}_{\mathrm{SB}} / \mathrm{BL}_{\mathrm{NSB}}$ ratios & & & & & & \\
\hline \multirow[t]{2}{*}{ S3B } & average plastome coverage : & CDS & 0.060 & 18 & 16 & 0.240 & 0.813 \\
\hline & BL for individual species & NCS & 0.041 & 18 & 16 & 0.166 & 0.870 \\
\hline \multirow[t]{2}{*}{ S3C } & $\mathrm{dN} / \mathrm{dS}:$ & CDS & $-7.3 \mathrm{E}-17$ & 16 & 14 & $-2.7 \mathrm{E}-16$ & 1.000 \\
\hline & $\begin{array}{l}\text { relative generation time for } \\
\text { individual species }\end{array}$ & & & & & & \\
\hline
\end{tabular}


Table S6. Estimate of natural selection acting on protein-coding chloroplast genes.

Ratios of non-synonymous to synonymous substitutions (dN/dS) from CDS alignments.

Subscript SB and NSB indicate seed-banking and non-seed-banking species, respectively.

\begin{tabular}{|c|c|c|}
\hline & $d N / d S$ & $\frac{\left(\mathrm{dN} / \mathrm{dS}_{\mathrm{sB}}\right)}{\left(\mathrm{dN} / \mathrm{dS}_{\mathrm{NSB}}\right)}$ \\
\hline Campanula patula & 0.279 & 0.984 \\
\hline Campanula rapunculoides $_{\mathrm{NSB}}$ & 0.284 & \\
\hline Cardamine $_{\text {amara }} \mathrm{SB}$ & 0.205 & 1.006 \\
\hline Cardamine impatiens $_{\mathrm{NSB}}$ & 0.204 & \\
\hline Carex flacca ${ }_{\mathrm{SB}}$ & 0.298 & 1.074 \\
\hline Carex acutiformis $_{\mathrm{NSB}}$ & 0.277 & \\
\hline Cirsium arvense $_{\mathrm{SB}}$ & 0.196 & 1.226 \\
\hline Cirsium eriophorum $_{\mathrm{NSB}}$ & 0.160 & \\
\hline Galium aparine $_{\mathrm{SB}}$ & 0.158 & 0.751 \\
\hline Galium odoratum $_{\mathrm{NSB}}$ & 0.210 & \\
\hline Geranium pusillum $_{\mathrm{SB}}$ & 0.342 & 1.000 \\
\hline Geranium pyrenaicum $_{\text {NSB }}$ & 0.342 & \\
\hline Lamium album $_{\mathrm{SB}}$ & 0.171 & 0.903 \\
\hline Lamium galeobdolon $_{\mathrm{NSB}}$ & 0.189 & \\
\hline Poa trivialis ${ }_{\mathrm{SB}}$ & 0.128 & 1.059 \\
\hline Poa nemoralis $s_{\mathrm{NSB}}$ & 0.121 & \\
\hline Ranunculus flammula $_{\mathrm{SB}}$ & 0.157 & 0.888 \\
\hline Ranunculus reptans $_{\mathrm{NSB}}$ & 0.176 & \\
\hline Silene vulgaris $_{\mathrm{SB}}$ & 0.183 & 1.030 \\
\hline Silene uniflora ${ }_{\mathrm{NSB}}$ & 0.178 & \\
\hline
\end{tabular}


bioRxiv preprint doi: https://doi.org/10.1101/156398; this version posted June 27, 2017. The copyright holder for this preprint (which was

not certified by peer review) is the author/funder, who has granted bioRxiv a license to display the preprint in perpetuity. It is made available under aCC-BY-NC-ND 4.0 International license.

Figure S1. Plastid gene content for the new plastomes. White boxes indicate the absence of a gene that is present in closely related species. Grey boxes indicate genes that are partial (dots) or contain frameshifts (s) whereas they are present in closely related species as longer complete open reading frames. Black boxes indicate genes that show the same stage in the reference, with filled boxes indicating genes present and apparently functional, whereas minus signs indicate an absence or possible loss of function (frame shift) of the gene, and dots a short size compared to other lineages, always both in the taxon of interest and closely related species. Therefore, whereas white and grey boxes indicate features that could be artefacts due to low-coverage regions, black boxes indicate biological features.

Attached as pdf 


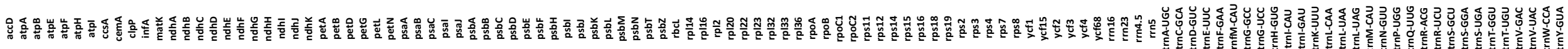

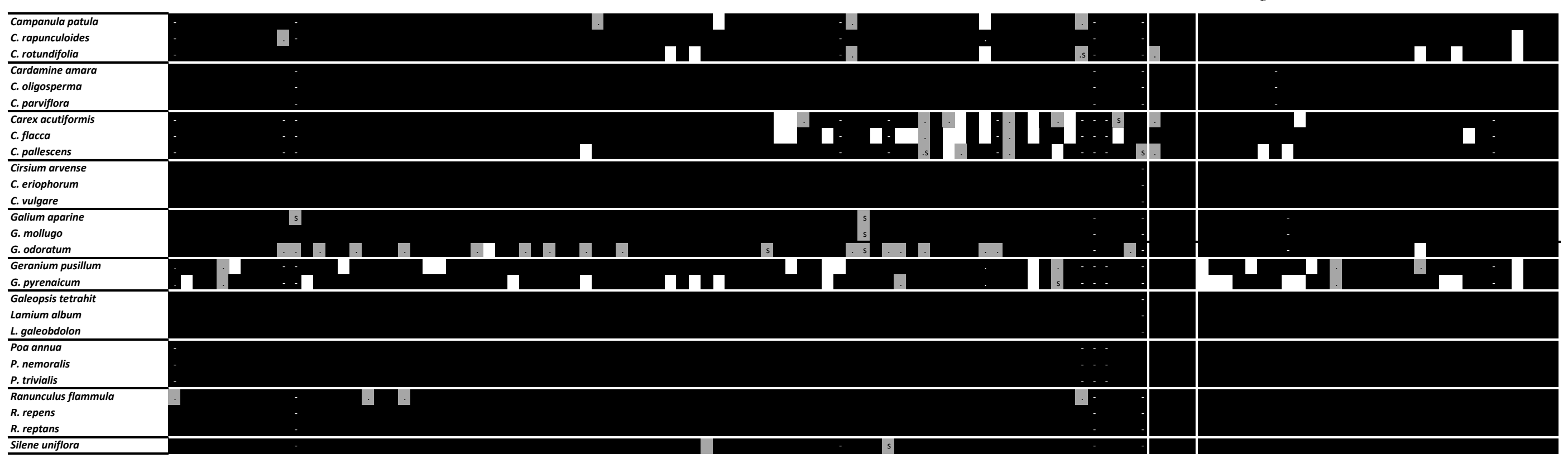

Present, and present in the reference

the or pseudogenized, but also absent or annotated as a psedogene in the reference

Short compared to most lineages, but also short in the reference

compared to the reference

Frame shift, whereas no frame shift in the reference

Absent, but present in the reference 
Figure S2. Bayesian phylogenetic trees used for relative substitution rate analyses. A. Topology obtained with the concatenated plastid coding sequences (CDS). B. Topology obtained with the CDS skimmed of loci yielding single-gene topologies conflicting the topology derived from all concatenated CDS. C. Topology obtained with the concatenated plastid non-coding sequences (NCS). D. Topology obtained with the NCS skimmed of loci yielding single-gene topologies conflicting the topology derived from all concatenated NCS. E. Topology obtained with the Nuclear ITS. F. Topology obtained with the nuclear ITS of Cardamine, with Geranium palmatum as outgroup. G. Topology obtained with the nuclear ITS of Poa. H. Topology obtained with the concatenated plastid CDS of 399 angiosperm taxa, including those used in this study. All topologies shown here are derived from nonpartitioned datasets, but those from partitioned datasets are qualitatively identical (see main text and Tables S2 and S3). 
bioRxiv preprint doi: https://doi.org/10.1101/156398; this version posted June 27,2017 . The copyright holder for this preprint (which was

not certified by peer review) is the author/funder, who has granted bioRxiv a license to display the preprint in perpetuity. It is made available under aCC-BY-NC-ND 4.0 International license.

A

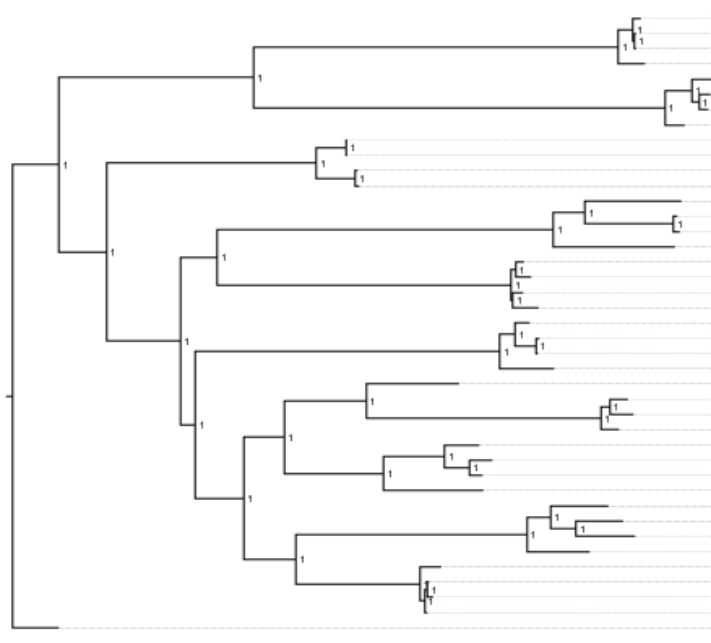

0.03 nucleotide substitutions per site
B

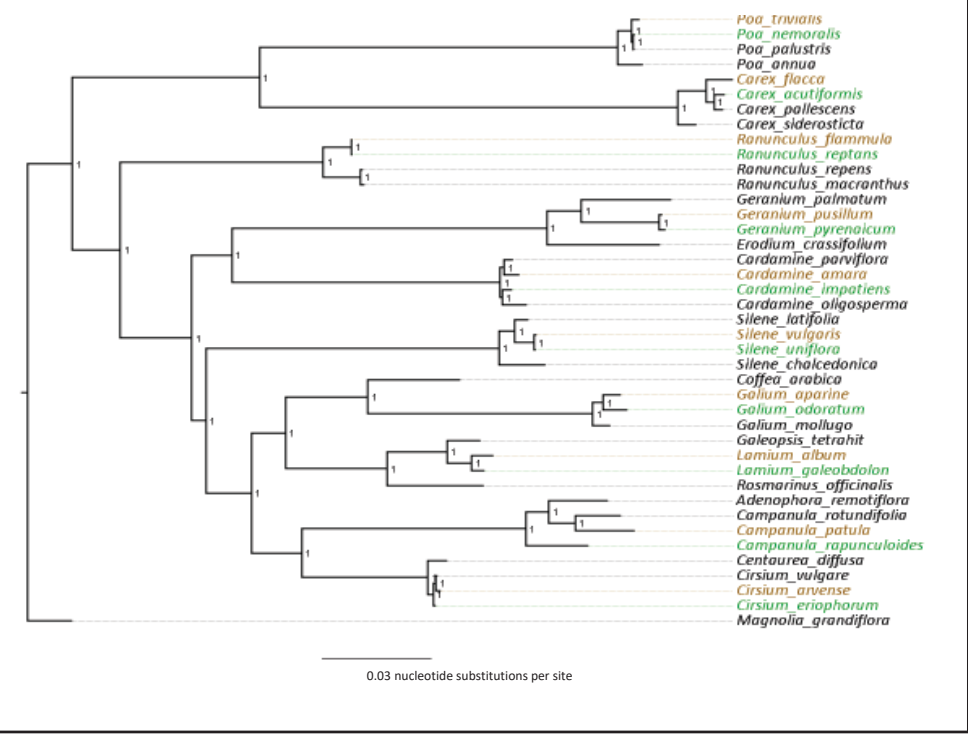

D

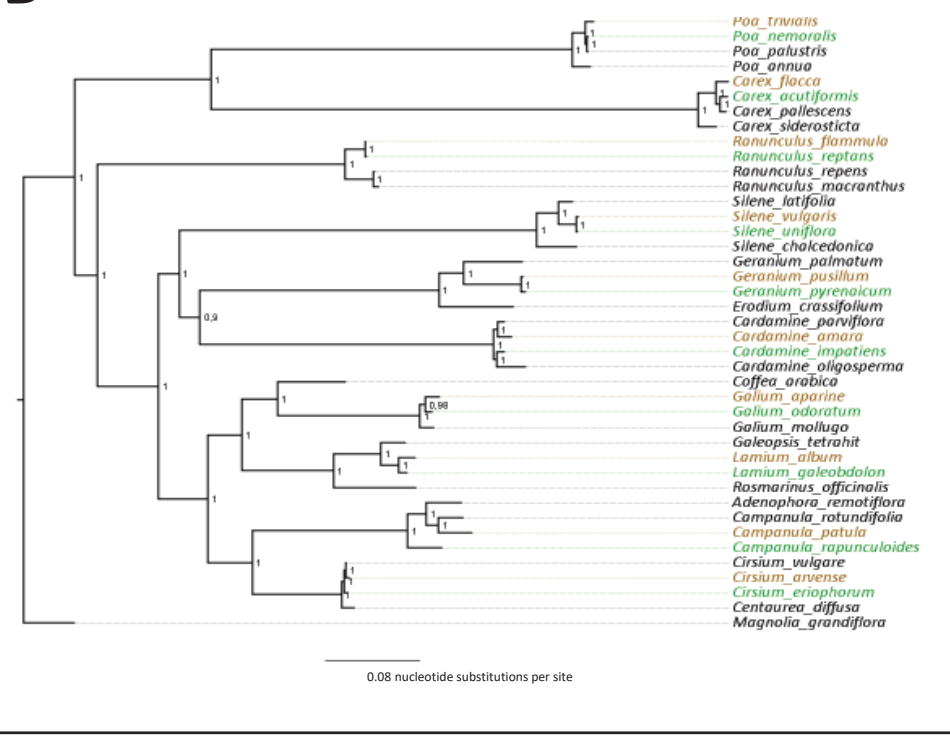

$\mathbf{F}$

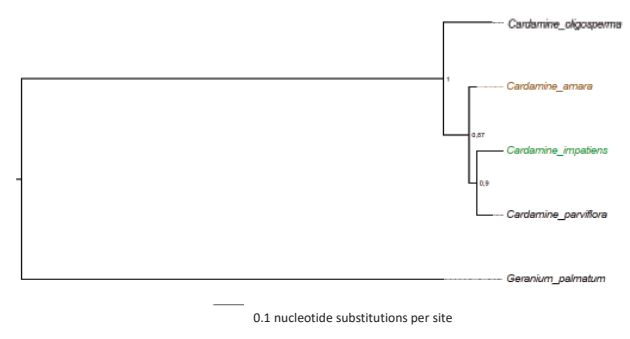

G

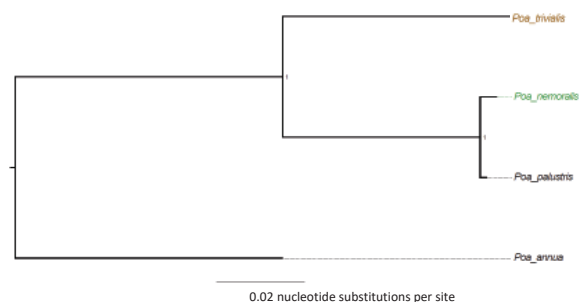


bioRxiv preprint doi: https://dol.org/10.1101/156398; this version posted June 27, 2017. The copyright holder for this preprint (which was not certified by peer review) is the author/funder, who has granted-bioRxiv a license to display the preprint in perpetuity. It is made available under aEC BY-NG-ND 4.0 International license.

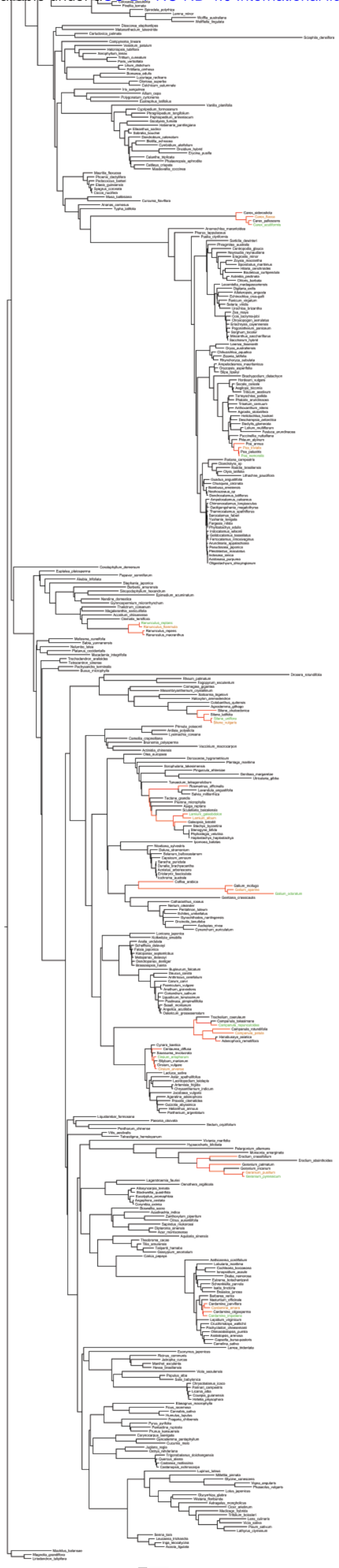




\section{Figure S3. Correlation analyses of substitution rates as a function of additional}

factors. A. Branch-lengths ratios $B L_{S B} / B_{N S B}$ (from the analysis of non-partitioned concatenated sequence alignments) as a function of average plastome coverage of the species pair. B. Branch-length as a function of average plastome coverage of individual species. C. $d N / d S$ as a function of generation time (relative to that of the other species of the pair). In C grey bars indicate SB species and black bars indicate NSB species. The inferior, equal and superior to signs indicate respectively that the species had a smaller, equal or larger generation time than its sister species.
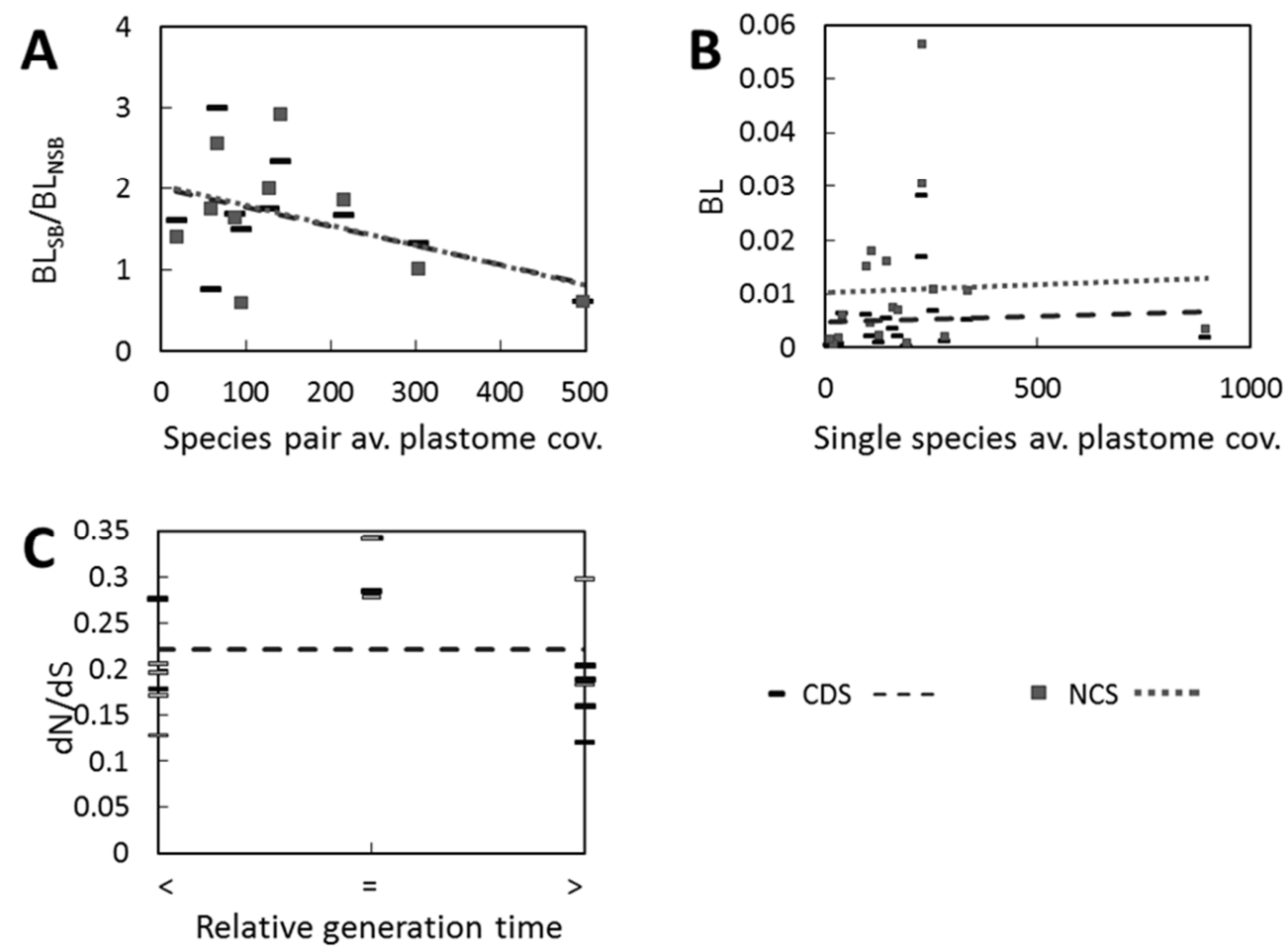
The following tables are attached as excel files.

Table S1. Species sampled in this study, with their voucher information, and accession numbers of plastomes newly generated and previously published. Information on the starting material and DNA quality, as well as coverage statistics are also provided.

Table S2. Branch lengths obtained from all Bayesian phylogenetic analyses. Branch lengths were not estimated for the genus-level trees of Cardamine and Campanula due to the impossibility to root them outside the species pair of interest.

Table S3. Summary of the substitution rate differences between seed-bankers and non-seed-bankers obtained in all Bayesian phylogenetic analyses. Branch lengths were not estimated for the genus-level trees of Cardamine and Campanula due to the impossibility to root them outside the species pair of interest.

Table S5. Biological information on the species involved in seed-banker/non-seedbanker comparisons.

Table S7. Accession numbers of whole plastomes, nuclear ITS and plastid regions used to build Figure $\mathrm{S} 2 \mathrm{H}$ and to perform polymorphism analyses in Lamium and Cardamine. 